\title{
Empresas de biotecnologia e biociências no Brasil: um panorama
}

\author{
Artigo submetido ao II Encontro Nacional de Economia Industrial
}

Nathalia Alves ${ }^{1}$, Marco Antônio Vargas ${ }^{2}$, Jorge Britto ${ }^{3}$

\begin{abstract}
Resumo
O objetivo artigo é apresentar um panorama sobre as empresas de biotecnologia e biociências constituídas sob o modelo de empreendimentos intensivos em conhecimento no Brasil, através da sistematização de resultados provenientes de trabalhos e pesquisas de campo encontrados na literatura técnica e acadêmica. Busca-se, ainda, a identificação e o mapeamento de empresas de biotecnologia que possuem aplicações no segmento de saúde humana, removendo um importante gargalo para o desenvolvimento de estudos voltados à micro e pequenas empresas de base tecnológica no segmento de fármacos e medicamentos biológicos. A análise está baseada em dados provenientes dos estudos: Bianchi (2013); ABDI (2012); CEBRAP e BRBIOTEC (2011); Biominas e PwC (2011); Biominas (2009); Razaie et al (2008); Biominas (2007); Biominas (2001) e Miglioli (2014). Foram utilizados também dados extraídos do Censo 2010 do Diretório dos Grupos de Pesquisa do Conselho Nacional de Desenvolvimento Científico e Tecnológico (CNPq), dos diretórios de empresas de biociências elaborados por Biominas e PwC (2011) e Biominas e SEBRAE (2014) e das páginas institucionais de empresas e incubadoras.
\end{abstract}

\begin{abstract}
The paper aims to present an overview of the biotechnology and bioscience companies established under the Knowledge-Intensive Entrepreneurship model in Brazil. It also aims to map Brazilian Biotechnology companies with applications in human health, removing a major bottleneck to study small innovative firms in biopharmaceuticals in Brazil. The analysis is based upon data gathered from the studies: Bianchi (2013); ABDI (2012); CEBRAP and BRBIOTEC (2011); Biominas and PwC (2011); Biominas (2009); Razaie et al (2008); Biominas (2007); Biominas (2001) and Miglioli (2014). Were also collected data from the Diretório dos Grupos de Pesquisa do Conselho Nacional de Desenvolvimento Científico e Tecnológico (CNPq) concerning the Census 2010, from the bioscience enterprise databases available on Biominas. PwC (2011) and Biominas. SEBRAE (2014), and from enterprisers and incubators institutional web sites.
\end{abstract}

Palavras-chave: Biotecnologia; Biociências; Empreendimentos baseados em conhecimentos.

\section{ABEIN Área 5: Inovação e mudanças técnica, organizacional e institucional Códigos JEL: L26, L65}

\footnotetext{
${ }^{1}$ Estudante do Programa de Pós-Graduação em Economia da Universidade Federal do Rio de Janeiro (PPGE-UFRJ).

${ }^{2}$ Professor da Faculdade de Economia da Universidade Federal Fluminense (UFF).

${ }^{3}$ Professor da Faculdade de Economia da Universidade Federal Fluminense (UFF).
} 


\section{Introdução:}

A biotecnologia entendida como manipulação de processos biológicos e organismos vivos para a obtenção de bens, processos e serviços - como a fabricação de bebidas e a transformação de alimentos não é uma prática nova. Foi, entretanto, a partir do final da década de 1970 e início da década de 1980 que surgiu a biotecnologia moderna, uma combinação de blocos de conhecimento e ferramentas tecnológicas, cujas aplicações transversais impactaram a heurística de solução de problemas e busca por inovações em diversos setores. O desenvolvimento das biociências ampliou a compreensão sobre processos biológicos em nível genético e molecular e abriu novas avenidas para inovação, inaugurando a emergência de um novo paradigma tecnológico. Em decorrência da transversalidade e da elevada pervasividade da nova tecnologia, muitas áreas de atividade foram influenciadas, dentre elas: (i) o segmento de saúde humana e setor farmacêutico; (ii) a produção e a engenharia de alimentos; (iii) a engenharia de novos materiais e a química fina; (iv) energia e meio ambiente; entre outros (MCKELVEY. ORSENIGO, 2001; BRINK et al., 2004).

Inicialmente, os avanços da biotecnologia foram perseguidos por empresas constituídas sob o formato de spin-offs acadêmicos. Shane (2004) define o conceito de Spin-off acadêmico como novas empresas fundadas com o objetivo de explorar uma peça de propriedade intelectual criada dentro de uma instituição acadêmica. Malerba e Mckelvey (2016) propõem um modelo mais abrangente de empreendimentos intensivos em conhecimentos descrito através do surgimento, da sobrevivência e do crescimento de novas empresas inovadoras, intensivas em conhecimentos e destinadas à exploração de oportunidades tecnológicas em diversos setores e contextos. Engloba-se, dessa forma, os conceitos de spin-off acadêmico e de startup tecnológica (empresa criada para a exploração de novas tecnologias).

As empresas de biotecnologia foram, historicamente, formadas através da associação entre pesquisadores acadêmicos, cientistas recém saídos de laboratórios corporativos de P\&D e gestores profissionais para aproveitar o espaço aberto pelas novas oportunidades tecnológicas, com apoio financeiro de fundos de capital de risco (venture capital) e de programas de fomento governamental. Observou-se o surgimento e a consolidação de empresas cuja atividade principal era a condução de pesquisa básica e a comercialização de resultados de pesquisa acadêmica através da venda ou do licenciamento de direitos de propriedade intelectual (ARORA. GAMBARDELLA, 1995; CORIAT et al.,2003).

Poucas tecnologias são propícias à geração de spin-offs e empreendimentos intensivos em conhecimento. A maioria das invenções acadêmicas são licenciadas diretamente para grandes firmas incumbentes, em função da existência de vantagens em escala de produção e comercialização. No caso da biotecnologia, algumas características relacionadas às biociências como: os longos prazos de desenvolvimento dos produtos; o locus de expertise no setor acadêmico; a base de conhecimentos complexa e emergente; o foco em qualidade e eficácia; a proteção efetiva de patentes; a natureza discreta das invenções; e a possibilidade de aplicação comercial direta dos métodos desenvolvidos são fatores que favoreceram o surgimento dos spin-offs e o domínio da industria de biotecnologia por micro e pequenas empresas baseadas em conhecimentos (SHANE, 2004).

Existem, contudo, limitações ao surgimento e ao crescimento dos empreendimentos intensivos em conhecimento. Gravaglia et al (2006) argumenta que a competitivade e a capacidade de crescimento das novas empresas de biotecnologia é minada em função da carência de economias de escala e escopo em produção; capacidade de distribuição e marketing; experiência na condução de longos e custosos testes clínicos; recursos financeiros e ativos complementares.

O surgimento, a sobrevivência e o crescimento das empresas de biotecnologia são processos condicionados por elementos característicos da estrutura de capacitações internas das firmas e por fatores externos que estão relacionados ao ambiente no qual as empresas estão inseridas. Os fatores internos são firma-específicos e tendem a variar de caso a caso. Os fatores externos possuem caráter sistêmico e afetam conjuntos de empresas inseridas em contextos e ambientes semelhantes. Entre este fatores destacam-se: i) A estrutura de ciência e tecnologia; ii) A capacidade de acessar fontes externas de conhecimentos; iii) A disponibilidade de fontes de fomento e financiamento; iv) Patentes e condições de apropriabilidade do capital intelectual; entre outros (PISANO, 2010).

O surgimento de novas firmas especializadas em biotecnologia dentro do Sistema Setorial de Inovação Farmacêutico é uma das mais interessantes manifestações das transformações imputadas pelo advento da biotecnologia moderna nas décadas nas décadas de 1970 e 1980. As novas bases de 
conhecimento alteraram a estrutura do processo de busca por novas drogas terapêuticas através da introdução de novos problemas, rotinas e heurísticas de solução em ambientes de incerteza fundamental. A consequência foi a reformulação da estrutura organizacional do setor farmacêutico pautada pela emergência de uma densa rede de colaborações e alianças estratégicas entre agentes e organizações heterogêneas. A necessidade de acesso a recursos financeiros e ativos complementares incentivou a emergência de relações de cooperação entre as novas empresas de biotecnologia e as grandes empresas farmacêuticas incumbentes. Os acordos de colaboração permitiram às empresas de biotecnologia a obtenção do volume adequado de recursos para financiar seus onerosos processos de P\&D e o acesso aos ativos complementares, como as estruturas de marketing e distribuição, das grandes empresas (ARORA. GAMBARDELLA, 1995; GRAVAGLIA et al., 2006; MCKELVEY. ORSENIGO, 2001).

As novas empresas dedicadas à biotecnologia seguiram um viés de especialização na provisão de tecnologias e serviços de P\&D em nichos específicos de conhecimento. As empresas estabelecidas passaram a formar vínculos com novas e sucessivas entrantes. A aquisição de tecnologias ofertadas pelas empresas de biotecnologia representava uma alternativa financeiramente mais vantajosa e menos arriscada para as grandes empresas farmacêuticas - visto que as tecnologias eram desenvolvidas com base em pesquisas acadêmicas financiadas com recursos públicos e exploradas por empreendimentos que assumiam os riscos da atividade inovadora e contavam com o apoio do capital de risco e de recursos públicos de fomento (ARORA. GAMBARDELLA, 1995; GRAVAGLIA et al., 2006). Dada a amplitude e a intensidade do avanço tecnológico, nenhuma grande empresa seria capaz de explorar sozinha todas os elementos e especificidades do horizonte de $\mathrm{P} \& \mathrm{D}$ em biotecnologia. $\mathrm{O}$ acesso à fontes externas de conhecimento - como universidades e empresas dedicadas à biotecnologia - era de certa forma inevitável. A maioria das empresas de biotecnologia mantiveram pelo menos um relacionamento contratual com uma empresa química ou farmacêutica (PISANO, 2010).

No Brasil, a incorporação da rota biotecnológica na indústria química e farmacêutica nacional é interpretada como uma questão estratégica nacional. Identifica-se a existência de uma janela de oportunidade para a inserção produtiva do país em segmentos intensivos em conhecimentos, de elevado valor agregado e cuja perspectiva é de crescimento substantivo da demanda de mercado no longo prazo. Os setores intensivos em conhecimentos são referidos na literatura acadêmica como potenciais indutores de crescimento econômico, de inovações e de processos de catching-up tecnológico. O avanço da produção nacional de fármacos e medicamentos produzidos por rotas biotecnológicas surge, dentro do contexto do Complexo Econômico Industrial da Saúde, como uma alternativa para o alívio das restrições e da dependência nacional em relação à importação de medicamentos estratégicos para o atendimento das demandas do Sistema Único de Saúde (SUS). A biotecnologia vem sendo alvo de políticas públicas no Brasil desde a década de 1980 e foi definida como uma área portadora de futuro desde a Política Industrial Tecnológica e de Comércio Exterior (PITCE), elaborada no ano de 2004. O status estratégico do segmento manteve-se em destaque ao longo do período recente e um ponto chave das políticas formuladas no país foi o estímulo às novas empresas dedicadas à biotecnologia constituídas sob o modelo de empreendimentos de base tecnológica (BIANCHI, 2013).

Este estudo busca construir um panorama sobre as empresas de biotecnologia e biociências constituídas sob o modelo de empreendimentos intensivos em conhecimento no Brasil. O objetivo do trabalho é quantificar e qualificar a indústria brasileira de biotecnologia e biociências à luz do modelo de empreendimentos intensivos em conhecimento, através da sistematização de resultados provenientes de trabalhos e pesquisas de campo encontradas na literatura técnica e acadêmica. Individualmente estes trabalhos contém informações relevantes sobre atividades intensivas em ciências da vida, entretanto ao serem combinados os dados se complementam dando origem a um panorama amplo capaz de endereçar questões como número de empresas, tamanho, idade, dispersão geográfica, formas de utilização da tecnologia, disponibilidade de produtos e serviços no mercado, captação de recursos, parcerias colaborativas com grandes empresas e Instituições de Ciência e Tecnologia (ICTs), mecanismos de apropriação e transferência de direitos de propriedade intelectual. Busca-se, ainda, identificar e mapear a existência de empresas de biotecnologia com aplicações no segmento de saúde humana e, desta forma, remover um importante gargalo identificado na literatura que restringe a capacidade de condução de estudos 
voltados especificamente às micro e pequenas empresas de biotecnologia inseridas no Sistema de Inovação Biofarmacêutico Brasileiro.

$\mathrm{O}$ artigo está estruturado em seis seções encabeçadas por esta introdução. Na segunda seção são apresentados os aspectos metodológicos, as definições de biotecnologia, as dificuldades envolvidas na construção de um panorama com base na compatibilização de dados provenientes de estudos metodologicamente diversos e a metodologia de identificação de empresas desenvolvida para esta pesquisa. $\mathrm{Na}$ terceira seção apresenta-se o panorama sobre as empresas brasileiras de biotecnologia e biociências. Entre os aspectos contemplados na análise, destacam-se: o número de empresas; classificação das empresas por área de atividade, idade, tamanho e perfil de aplicação da biotecnologia; concentração regional; formas de articulação com a estrutura de ciência e tecnologia; fontes de fomento e financiamento; depósito de patentes e mecanismos de transferência de tecnologia. A quarta seção apresenta os resultados do estudo de identificação e o mapeamento das empresas brasileiras de biotecnologia em saúde humana. Na quinta seção são apresentadas as considerações finais do artigo, seguidas da seção de referências bibliográficas.

\section{Aspectos metodológicos}

Para cumprir com os objetivos de traçar um panorama que quantifique e qualifique a indústria brasileira de biotecnologia e biociências e mapear as empresas de biotecnologia do segmento de saúde humana no Brasil, selecionaram-se sete estudos cujos principais resultados foram sistematizados neste artigo: Bianchi (2013); ABDI (2012); CEBRAP e BRBIOTEC (2011); Biominas e PwC (2011); Biominas (2009); Biominas (2007); Biominas (2001). Foram utilizados como fontes complementares de dados: os estudos Razaie et al (2008) e Miglioli (2014), os diretórios de empresas de biociências elaborados por Biominas e PwC (2011) e Biominas e SEBRAE (2014), dados extraídos do Censo 2010 do Diretório dos Grupos de Pesquisa do Conselho Nacional de Desenvolvimento Científico e Tecnológico (CNPq) e informações fornecidas pelas páginas institucionais das empresas e de incubadoras.

Os trabalhos selecionados apresentam resultados diferentes em termos de número de empresas identificadas, porém coerentes entre si no que concerne a qualificação da indústria. Os dados foram sistematizados conforme a disponibilidade dos mesmos em cada trabalho. As diferenças quantitativas provêm de diferenças metodológicas entre os estudos e das dificuldades envolvidas na definição de uma atividade multidisciplinar e interdisciplinar fundada sobre uma base de conhecimentos emergente, mutável e complexa ${ }^{4}$. Verifica-se na literatura uma ausência de consenso sobre uma definição padrão e universal do que é a biotecnologia (BRINK et al., 2004; BIANCHI, 2013).

Em Biominas (2001), a biotecnologia foi definida com uma aplicação de tecnologias habilitadoras que envolvem a manipulação de organismos vivos, células e moléculas com a finalidade de gerar produtos e serviços. Foram incorporadas no estudo empresas fornecedoras de insumos e equipamentos em áreas consideradas correlatas à biotecnologia. A definição utilizada mostrou-se demasiado ampla e resultou em uma discrepância grande com relação aos números encontrados nos estudos posteriores.

O estudo Biominas (2007) optou por uma definição de biotecnologia sugerida pela revista Nature Biotechnology segundo a qual: uma empresa de biotecnologia é caracterizada pela aplicação tecnológica de organismos vivos, processos e sistemas biológicos, cuja atividade comercial principal está relacionada à realização de atividades de pesquisa e desenvolvimento e à provisão de produtos e serviços especializados.

Biominas (2009) é o primeiro estudo a utilizar a definição das técnicas de biotecnologia fornecida pela OCDE (2005), uma tendência seguida por CEBRAP e BRBIOTEC (2011); Biominas e PwC (2011) e ABDI (2012). Nestes estudos, a biotecnologia é descrita como a "Aplicação da ciência e da tecnologia aos organismos vivos, bem como a partes, produtos e modelos dos mesmos, para alterar materiais vivos ou não vivos com finalidade de produzir conhecimentos, produtos e serviços" (OCDE, 2005, p. 9). As empresas de biotecnologia são aquelas que utilizam pelo menos uma técnica de biotecnologia para a geração de bens, serviços ou para a realização de pesquisa e desenvolvimento. As atividades biotecnológicas definidas pela OCDE encontram-se descritas no Quadro 1, abaixo.

\footnotetext{
${ }^{4}$ Existe uma distinção entre a base de conhecimentos técno-científicos e a definição de uma indústria ou setor de atividade de biotecnologia. A biotecnologia, em sentido estrito, é um conjunto de tecnologias e conhecimentos com possíveis aplicações em diversos setores industriais. Entretanto, é possível fazer referência a uma indústria de biotecnologia composta por diversas empresas, com características similares, cuja atividade principal é a condução de pesquisa, desenvolvimento e inovação (PD\&I) em biotecnologia (BRINK et al., 2004).
} 


\section{Quadro 1 - Lista de técnicas de biotecnologia definidas pela OCDE}

\begin{tabular}{|l|l|}
\hline DNA/RNA: & $\begin{array}{l}\text { Genômica; farmacogenômica; sondas gênicas; engenharia genética, sequenciamento, síntese e } \\
\text { amplificação de DNA/RNA; perfil de expressão gênica; e uso de tecnologia antisense. }\end{array}$ \\
\hline Proteínas e outras moléculas: & $\begin{array}{l}\text { Sequenciamento, síntese e engenharia de proteínas e peptídeos (inclusive hormônios de alto peso } \\
\text { molecular); métodos de endereçamento de drogas de alto peso molecular; análise proteômica; isolamento } \\
\text { e purificação de proteínas; sinalização e identificação de receptores celulares. }\end{array}$ \\
\hline $\begin{array}{l}\text { Cultura e engenharia de células e } \\
\text { de tecidos: }\end{array}$ & $\begin{array}{l}\text { Cultura de células e tecidos; engenharia de tecidos; fusão celular; vacinas e imunomoduladores; } \\
\text { manipulação de embriões. }\end{array}$ \\
\hline $\begin{array}{l}\text { Técnicas de processamento } \\
\text { biotecnológico: }\end{array}$ & $\begin{array}{l}\text { Fermentação utilizando bioreatores, bioprocessamento, biolixiviação, biopolpação, biobranqueamento, } \\
\text { biodessulfurização, biorremediação, biofiltração e fitorremediação. }\end{array}$ \\
\hline Vetores gênicos e de RNA: & Terapia gênica e vetores virais. \\
\hline Bioinformática: & $\begin{array}{l}\text { Construção de base de dados de genomas e sequências proteicas; modelamento de processos biológicos } \\
\text { complexos, inclusive sistemas biológicos. }\end{array}$ \\
\hline Nanobiotecnologia: & $\begin{array}{l}\text { Utilização de ferramentas e processos de nano e microfabricação para o estudo de sistemas biológicos e } \\
\text { aplicações de endereçamento de drogas; aplicações em diagnósticos e outros. }\end{array}$ \\
\hline
\end{tabular}

Fonte: Elaboração própria com base em OCDE (2005) e Biominas (2009).

Bianchi (2013) propõe a adoção de uma definição mais estreita, excluindo-se técnicas de biotecnologia tradicional, como técnicas de processamento e fermentação, e as atividades de bioinformática. Segundo o autor, a biotecnologia moderna consiste em um corpo de conhecimentos e em um amplo conjunto de técnicas e procedimentos que atuam de forma integrada sobre os atributos de células, moléculas, DNA e proteínas para a criação ou modificação de produtos e processos com aplicações específicas em diversos setores de atividade.

Os estudos da Biominas $(2007 ; 2009)$ e Biominas e PWC (2011) optaram pela ampliação do escopo do objeto através da utilização do conceito de biociências definido como "empreendimentos com um ponto em comum: o desenvolvimento de produtos e serviços baseados nos avanços recentes do conhecimento sobre os processos e sistemas biológicos" (BIOMINAS, 2009: p.10). Apesar dos termos biotecnologia e biociências serem utilizados muitas vezes como sinônimos, o conceito de biociências é mais amplo e contém a definição de biotecnologia. A justificativa apresentada pela utilização do conceito mais amplo é a possibilidade de inclusão de empresas voltadas à validação de medicamentos farmacêuticos através da condução de ensaios clínicos e pré-clínicos. O resultado da utilização do conceito de biociências é um aumento no número de empresas identificadas pelos estudos e a simplificação do processo de identificação.

Os estudos selecionados utilizaram a definição de biotecnologia por áreas de atividade definidas no Quadro 2. Biominas e PwC (2011) propõe, ainda, uma definição da área de agronegócios que representa uma combinação das atividades das áreas de saúde animal, agricultura e biocombustíveis.

\section{Quadro 2 - Biotecnologia por área de atividade}

\begin{tabular}{|l|l|}
\hline Saúde humana: & $\begin{array}{l}\text { Desenvolvimento de drogas, vacinas, terapia celular, pesquisas com células tronco, desenvolvimento de novas } \\
\text { fórmulas, diagnósticos e proteínas recombinantes voltadas ao atendimento das demandas de saúde humana. }\end{array}$ \\
\hline Saúde animal: & $\begin{array}{l}\text { Clonagem e melhoramentos genéticos, drogas e vacinas veterinárias, desenvolvimento de novas tecnologias em } \\
\text { reprodução animal. }\end{array}$ \\
\hline Agricultura: & Biofertilizante e biopesticidas, sementes e plantas transgênicas, clonagem e melhoramento genético. \\
\hline Bioenergia: & Desenvolvimento de novas tecnologias em biocombustíveis. \\
\hline Meio Ambiente: & Biorremediação, manejo de resíduos e recuperação de áreas degradadas. \\
\hline Insumos e Reagentes: & Enzimas, reagentes para kits de diagnóstico, moléculas bioativas, anticorpos. \\
\hline Misto/ Outras áreas: & Desenvolvimento de diagnóstico celular para diversas áreas, bioinformática, CROs e consultorias especializadas. \\
\hline
\end{tabular}

Fonte: CEBRAP e BRBIOTEC (2011)

São reconhecidas as dificuldades envolvidas na compatibilização de estudos que utilizam definições e metodologias distintas para a identificação de empresas inseridas em atividades tecnológicas multidisciplinares, interdisciplinares e dinâmicas. Por esta razão, o que está proposto neste artigo é uma aproximação do universo de empresas de biotecnologia e biociências instaladas no país, através da exposição e comparação dos principais resultados encontrados na literatura técnica e acadêmica, propiciando a construção de um panorama que permita avaliar a posição do Brasil no que concerne a consolidação das atividades relacionadas ao uso da biotecnologia.

A identificação das empresas destacou-se como um problema relevante. Apesar dos estudos indicarem a existência, em média, de 300 empresas de biociências no país e de, pelo menos, 175 empresas de biotecnologia, os dados dessas empresas não são divulgados de forma integral e há pouca informação 
sobre a metodologia de coleta de dados. A limitação de informações e de uma identificação clara das empresas de biociências e de biotecnologia restringe a realização de pesquisas acadêmicas sobre as empresas de segmentos específicos de atividade. Apresenta-se neste artigo um primeiro esforço direcionado à identificação e mapeamento das empresas de biotecnologia que são formadas sob o modelo de empresas de base tecnológica e tem suas atividades voltadas a aplicações em saúde humana.

Para a identificação das empresas, consolidou-se uma lista com as razões sociais de empresas e instituições entrevistadas por ABDI (2012), CEBRAP e BRBIOTEC (2012) e Miglioli (2015). Adicionaram-se à listagem, os dados de empresas contidos no Diretório de Empresas de Biociências do Brasil elaborado pela Biominas e PwC (2011) e no Diretório de Empresas do Setor de Biociências em Minas Gerais disponibilizado pela Biominas e SEBRAE (2014). Para complementar a identificação, foram visitados os sites das incubadoras Supera, Habitat, COPPE-UFRJ, BIO-RIO e CIETEC e utilizados dados do Censo 2010 do Diretório dos Grupos de Pesquisa do $\mathrm{CNPq}^{5}$. Adicionaram-se 23 nomes de empresas de biociências que não estavam inicialmente incluídas na listagem através da consulta às páginas das incubadoras e 19 nomes provenientes do Diretório dos Grupos de Pesquisa do CNPq. As empresas foram classificadas conforme áreas de atividades listadas no Quadro 2 e tiveram seus websites institucionais identificados. Para coletar informações empresariais como razão social, nome fantasia, CNPJ, CNAE e localização utilizaram-se a base de dados do site Econodata.com.br e do site EmpresasCNPJ.com.

Excluíram-se da listagem aquelas empresas cujos dados não puderam ser encontrados ou eram insuficientes para a identificação de suas atividades. Excluíram-se, também, empresas que apresentavam fortes indícios de extinção, tais como avisos de liquidação voluntária atrelados ao número do CNPJ. Mantiveram-se na listagem empresas cujos sites institucionais encontravam-se inativos ou indisponíveis, mas cujos CNPJ encontravam-se ativos. Para as empresas cujos sites estavam inativos ou indisponíveis, foram utilizadas as informações divulgadas nos diretórios da Biominas (BIOMINAS. PWC, 2011; BIOMINAS. SEBRAE, 2014) e nas incubadoras de empresas. Foram excluídas da amostra: instituições de ciência e tecnologia, laboratórios oficiais e empresas cujas atividades não se enquadravam na definição de biociências. Optou-se, também, pela exclusão de grandes empresas farmacêuticas nacionais, joint-ventures farmacêuticas, empresas multinacionais instaladas no país e empresas voltadas apenas à produção de máquinas e equipamentos, devido ao enfoque pretendido em micro e pequenas empresas de base tecnológica intensivas no uso de biotecnologia e de biociências.

Selecionaram-se as empresas envolvidas em atividades de saúde humana e buscou-se por empresas que utilizassem pelo menos uma técnica de biotecnologia (Quadro 1). A seleção das empresas foi realizada com base nas informações disponíveis nos sites institucionais e nos diretórios da Biominas (BIOMINAS. PWC, 2011; BIOMINAS. SEBRAE, 2014). Optou-se pela exclusão de empresas voltadas à produção suplementos alimentares (alimentos probióticos e proteicos) e empresas dedicadas à pesquisa, desenvolvimento e produção de dermocosméticos e nutricosméticos. Excluíram-se, também, as empresas voltadas ao desenvolvimento e produção de fitoterápicos e as empresas mistas que estavam mais orientadas às atividades de agronegócios.

As empresas de biotecnologia em saúde humana identificadas foram agrupadas em quatro categorias de acordo com suas atividades: i) Grupo 1 - Empresas envolvidas em múltiplas técnicas de biotecnologia em saúde humana; ii) Grupo 2 - Empresas envolvidas em engenharia tecidual e biomateriais; iii) Grupo 3 Empresas envolvidas em pesquisa, desenvolvimento e produção de enzimas e kits de diagnóstico; iv) Grupo 4: laboratórios clínicos e bancos de células. O agrupamento foi uma solução encontrada para facilitar a exposição dos dados ao leitor. Foram analisados para cada grupo o número de empresas, a localização por unidades da federação, a idade das empresas com base no ano de cadastro do CNPJ, a interação com universidades com base nos dados do Censo 2010 do Diretório dos Grupos de Pesquisa do CNPq e a classificação das empresas de acordo com a Classificação Nacional de Atividade Econômica (CNAE).

\footnotetext{
${ }^{5}$ Foram avaliadas as empresas e instituições interativas classificadas sob os ramos de atividade Fabricação de Produtos Farmoquímicos e Farmacêuticos e Pesquisa e Desenvolvimento Científico e sob as áreas de conhecimento: Bioquímica; Biofísica; Biologia Geral; Genética; Imunologia; Medicina; Microbiologia; Morfologia; Parasitologia; Farmacologia; Farmácia e Fisiologia. Para informações metodológicas detalhadas consultar Alves (2017).
} 


\section{Um panorama sobre as empresas de biotecnologia e biociências no Brasil.}

Estima-se que existam atualmente um número em torno de 271 e 338 empresas de biociências e entre 175 a 240 empresas de biotecnologia instaladas no país (Tabela 1).

Tabela 1 - Número de empresas de biociências e biotecnologia no Brasil

\begin{tabular}{|c|c|c|}
\hline Fonte & Empresas de biociências & Empresas de biotecnologia \\
\hline Bianchi (2013) & 338 & 175 \\
\hline ABDI (2012) & - & 240 \\
\hline CEBRAP e BRBIOTEC (2011) & - & 237 \\
\hline Biominas e PwC (2011) & 271 & 143 \\
\hline Biominas (2009) & 253 & 109 \\
\hline Biominas (2007) & 181 & 71 \\
\hline Biominas (2001) & - & 304 \\
\hline
\end{tabular}

Fonte: Elaboração própria com base nos estudos listados na tabela.

As técnicas de biotecnologia propiciam aplicações em muitos setores de atividade. O segmento que reúne o maior número de empresas de biociências e biotecnologia brasileiras é saúde humana (34\% em média), seguido de saúde animal (22\% em média); agricultura (18\% em média) e insumos e reagentes (17\% em média), conforme dados apresentados na Tabela 2 abaixo.

Tabela 2 - Empresas de biotecnologia e biociências por área de atividade (\%)

\begin{tabular}{|c|c|c|c|c|c|c|c|c|}
\hline \multirow[b]{2}{*}{ Fonte } & \multirow[b]{2}{*}{ 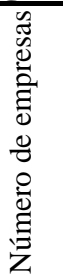 } & \multirow[b]{2}{*}{ 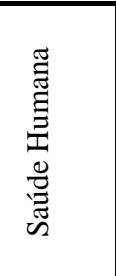 } & \multicolumn{3}{|c|}{ Agronegócios } & \multirow[b]{2}{*}{ 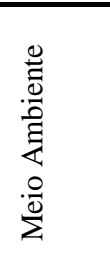 } & \multirow[b]{2}{*}{ 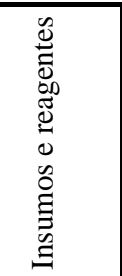 } & \multirow{2}{*}{ 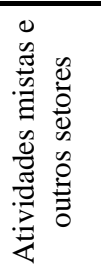 } \\
\hline & & & 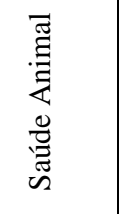 & 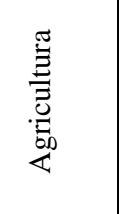 & 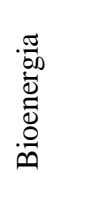 & & & \\
\hline $\operatorname{ABDI}(2012)^{1^{*}}$ & 100 & $49 \%$ & $31 \%$ & $22 \%$ & $11 \%$ & $14 \%$ & - & $22 \%$ \\
\hline CEBRAP e BRBIOTEC $(2011)^{2^{*}}$ & 237 & $39,70 \%$ & $14,30 \%$ & $9,70 \%$ & $5,10 \%$ & $9,70 \%$ & $13,10 \%$ & $8,40 \%$ \\
\hline Biominas e PwC $(2011)^{3}$ & 103 & $33 \%$ & \multicolumn{3}{|c|}{$31 \%$} & $6 \%$ & $18 \%$ & $12 \%$ \\
\hline Biominas (2009) ${ }^{4}$ & 102 & $30,80 \%$ & $14,00 \%$ & $18,00 \%$ & $4,40 \%$ & $8,00 \%$ & $16,00 \%$ & $8,00 \%$ \\
\hline Biominas $(2007)^{5^{*}}$ & 181 & $16,90 \%$ & $18,30 \%$ & $22,50 \%$ & $4,20 \%$ & $14,10 \%$ & $21,10 \%$ & $2,80 \%$ \\
\hline Média por área (\%) & & $34 \%$ & $22 \%$ & $18 \%$ & $\overline{6 \%}$ & $10 \%$ & $17 \%$ & $11 \%$ \\
\hline
\end{tabular}

*Empresas de biotecnologia

Fonte: Elaboração própria com base nos estudos listados na tabela.

As empresas de biociências e de biotecnologia brasileiras são, em sua maioria, empresas jovens. A série de estudos realizados pela fundação Biominas indica que entre $32 \%$ e $51 \%$ das empresas possuem até 5 anos de idade. Bianchi (2013) indica que 32\% das empresas possuem até 7 anos, ao passo que $36 \%$ possuem entre 7 e 12 anos, conforme dados dispostos na Tabela 3.

A porcentagem de empresas por ano de fundação tende a variar entre os estudos conforme as amostras selecionadas. Os estudos revisados apontam que cerca de $70 \%$ das empresas têm até 10 ou 12 anos de idade. As empresas foram criadas, majoritariamente, após o ano 2000. O cálculo de anos de vida foi feito com relação à data de divulgação de cada estudo. Não há como avaliar se há um processo de envelhecimento ou de renovação da população de empresas com base em amostras díspares.

Tabela 3 - Empresas de biotecnologia e biociências por idade (\%)

\begin{tabular}{|c|c|c|c|c|c|c|}
\hline \multirow{2}{*}{$\begin{array}{c}\text { CEBRAP e } \\
\text { BRBIOTEC }(2011)^{*}\end{array}$} & \multirow{2}{*}{$\begin{array}{c}\text { Número de } \\
\text { empresas } \\
214 \\
\end{array}$} & \multicolumn{4}{|c|}{ Até 11 anos } & Acima de 11 anos \\
\hline & & \multicolumn{4}{|c|}{$73 \%$} & $27 \%$ \\
\hline \multirow{2}{*}{ Bianchi (2013) ${ }^{*}$} & \multirow[b]{2}{*}{92} & \multirow{2}{*}{\multicolumn{2}{|c|}{$\frac{\text { Até } 7 \text { anos }}{32 \%}$}} & \multirow{2}{*}{\multicolumn{2}{|c|}{$\frac{8-12 \text { Anos }}{36 \%}$}} & Acima de 13 anos \\
\hline & & & & & $\%$ & $28 \%$ \\
\hline \multirow{2}{*}{ Biominas e PwC (2011) } & \multirow[b]{2}{*}{103} & Até 2 anos & 2 -5 Anos & $5-10$ Anos & $10-15$ Anos & Acima de 15 anos \\
\hline & & $6 \%$ & $38 \%$ & $29 \%$ & $9 \%$ & $18 \%$ \\
\hline Biominas (2009) & 102 & $12,50 \%$ & $19,80 \%$ & $35,40 \%$ & $15,60 \%$ & $16,70 \%$ \\
\hline Biominas (2007) ${ }^{*}$ & 181 & $26,70 \%$ & $23,90 \%$ & $21,10 \%$ & $9,90 \%$ & $18,30 \%$ \\
\hline
\end{tabular}

*empresas de biotecnologia

Fonte: Elaboração própria com base nos estudos listados na tabela. 
Existem duas alternativas possíveis para avaliar o tamanho de uma empresa: o faturamento bruto anual e o número de funcionários. Com base na Lei Complementar $\mathrm{N}^{\circ} 123$ de 14 de dezembro de $2006^{6}$ que define o tamanho da empresa com base em seu faturamento, estima-se que cerca de $50 \%$ dos empreendimentos brasileiros de biociências e de biotecnologia são microempresas. As micro e pequenas empresas representam mais de $70 \%$, em média, dos empreendimentos de biotecnologia e biociências do Brasil (Tabela 4).

Tabela 4 - Empresas de biotecnologia e biociências por receita bruta anual (\%)

\begin{tabular}{|c|c|c|c|c|c|c|}
\hline Fonte & $\mathrm{N}$ & Sem receitas & $\begin{array}{c}\text { Até } \\
\mathrm{R} \$ 240 \text { mil }\end{array}$ & $\begin{array}{c}\mathrm{R} \$ 240 \text { mil a } \\
\mathrm{R} \$ 2,4 \text { milhões }\end{array}$ & $\begin{array}{c}\mathrm{R} \$ 2,4 \text { milhões a } \\
\mathrm{R} \$ 12 \text { milhões }\end{array}$ & $\begin{array}{c}\text { Mais de R\$ } 12 \\
\text { milhões }\end{array}$ \\
\hline ABDI (2012) ${ }^{*}$ & 104 & $22 \%$ & $31 \%$ & $21 \%$ & $26 \%$ & - \\
\hline CEBRAP e BRBIOTEC (2011) ${ }^{*}$ & 141 & $21 \%$ & $29 \%$ & $27 \%$ & $14 \%$ & $10 \%$ \\
\hline \multirow{2}{*}{ Biominas e PwC (2011) } & & Sem receitas & \multicolumn{2}{|c|}{ Até RS\$ 1 milhão } & \multicolumn{2}{|c|}{ Mais de $\mathrm{R} \$ 1$ milhão } \\
\hline & 103 & $18 \%$ & \multicolumn{2}{|c|}{$54 \%$} & \multicolumn{2}{|c|}{$29 \%$} \\
\hline Biominas (2009) & 102 & $20 \%$ & \multicolumn{2}{|c|}{$49 \%$} & \multicolumn{2}{|c|}{$31 \%$} \\
\hline
\end{tabular}

*Empresas de biotecnologia; $\mathrm{N}=$ Número de empresas

Fonte: Elaboração própria com base nos estudos listados na tabela.

O Serviço Brasileiro de Apoio às Micro e Pequenas Empresas (SEBRAE) propõe a utilização do critério de número de funcionários como um indicativo para o tamanho da empresa. Consideram-se microempresas aquelas que empregam até 19 funcionários; pequenas aquelas com 20 a 99 funcionários; as empresas de porte médio aquelas com 100 a 499 funcionários; e grandes as empresas com mais de 500 funcionários. O percentual de microempresas na indústria de biotecnologia brasileira é um valor estimado entre $68 \%$ e $78 \%$ das amostras selecionadas pelos estudos revisados, enquanto o percentual de empresas pequenas varia entre $17 \%$ e $25 \%$. Ou seja, pelo critério de número de funcionários, as micro e pequenas empresas constituem mais de $90 \%$ da indústria de biociências e biotecnologia brasileira (Tabela 5).

Tabela 5 - Empresas de biotecnologia e biociências por pessoal ocupado (\%)

\begin{tabular}{|c|c|c|c|c|c|c|}
\hline Fonte & Número de empresas & Até 10 & 11 a 20 & 21 a 50 & 51 a 100 & Mais de 100 \\
\hline ABDI (2012)* & 96 & $65 \%$ & $12 \%$ & \multicolumn{2}{|c|}{$17 \%$} & $7 \%$ \\
\hline CEBRAP e BRBIOTEC $(2011) *$ & 138 & $46 \%$ & $19 \%$ & $20 \%$ & $6 \%$ & $9 \%$ \\
\hline Biominas e PwC (2011) & 103 & $53 \%$ & $13 \%$ & $21 \%$ & $7 \%$ & $6 \%$ \\
\hline Biominas (2009) & 102 & $51 \%$ & $27 \%$ & $14 \%$ & & \\
\hline
\end{tabular}

*Empresas de biotecnologia

Fonte: Elaboração própria com base nos estudos listados na tabela.

O estudo da ABDI (2012) aponta que uma parcela significativa das empresas de biotecnologia ${ }^{7}$ declarou a utilização de técnicas de engenharia genética (uso de técnicas de DNA e RNA); processamento biotecnológico (fermentação, biofiltragem e biorremediação); síntese de proteínas; manipulação de moléculas e engenharia de tecidos vivos. As técnicas de biotecnologia foram utilizadas com maior frequência nas etapas de $\mathrm{P} \& \mathrm{D}$ de produtos e processos, e com menor frequência na fase de produção. Apenas $26 \%$ das empresas declararam possuir produtos no mercado e $19 \%$ produtos e serviços. Cerca de $83 \%$ das empresas declararam estar em fase de desenvolvimento em produtos biotecnológicos. Quando questionadas sobre serviços biotecnológicos: $49 \%$ das empresas declararam já terem serviços biotecnológicos no mercado e 79\% estavam em fase de desenvolvimento de serviços biotecnológicos. As evidências fornecidas pela ABDI (2012) são coerentes com um cenário de empresas jovens e que se encontram em fase pré-operacional.

As empresas de biotecnologia e biociências do país apresentam uma elevada concentração espacial na região sudeste. Os dados da Tabela 6 indicam que mais de $70 \%$ das empresas estão localizadas nesta região. A segunda região com o maior percentual de empresas é a região sul com cerca de $14 \%$ das empresas, seguida da região nordeste que detém cerca de $6 \%$ dos empreendimentos.

\footnotetext{
${ }^{6}$ Considera-se microempresa: a sociedade empresária, a sociedade simples, a empresa individual de responsabilidade limitada e o empresário que aufira, em cada ano-calendário, receita bruta igual ou inferior a $\mathrm{R} \$ 360.000,00$ reais. Empresas de pequeno porte, por sua vez, são aquelas cuja receita bruta, em cada ano calendário, é superior a $\mathrm{R} \$ 360.000,00$ reais e igual ou inferior a $\mathrm{R} \$ 3.600 .000,00$ reais (BRASIL, 2006).

${ }^{7}$ Em uma amostra de 100 empresas (ABDI, 2012).
} 
Com base nos percentuais representados na Tabela 6, calculou-se um índice de concentração conhecido como Herfindahl-Hirschman Index (HHI), somando-se os quadrados dos percentuais de empresas por região para cada um dos estudos revisados. Quanto maior e mais próximo de 1 for o valor do HHI, maior é a concentração geográfica da indústria. Os índices obtidos variaram entre 0,55 e 0,64, refletindo uma concentração relativamente alta.

Tabela 6 - Empresas de biotecnologia e biociências por região do país (\%)

\begin{tabular}{l|r|rrrrrr}
\hline Fonte & $\begin{array}{c}\text { Número de } \\
\text { empresas }\end{array}$ & Sudeste & Sul & Nordeste & Centro-Oeste & Norte & HHI \\
\hline ABDI (2012)* & 106 & $72,0 \%$ & $17,0 \%$ & $8,0 \%$ & $1,0 \%$ & $2,0 \%$ & 0,55 \\
\hline CEBRAP e BRBIOTEC (2011) & 237 & $78,1 \%$ & $13,9 \%$ & $6,3 \%$ & $1,6 \%$ & $0,0 \%$ & 0,63 \\
\hline Biominas e PwC (2011) & 103 & $74,9 \%$ & $14,4 \%$ & $6,3 \%$ & $2,6 \%$ & $0,9 \%$ & 0,59 \\
\hline Biominas (2009) & 102 & $71,9 \%$ & $15,0 \%$ & $6,3 \%$ & $5,1 \%$ & $1,5 \%$ & 0,55 \\
\hline Biominas (2007) & 181 & $79,0 \%$ & $10,5 \%$ & $5,0 \%$ & $4,4 \%$ & $1,1 \%$ & 0,64 \\
\hline
\end{tabular}

*Empresas de biotecnologia

Fonte: Elaboração própria com base nos estudos listados na tabela.

O fenômeno da concentração espacial fica ainda mais evidente quando avaliamos a distribuição geográfica por estados ou unidades da federação (Tabela 7). Pelo menos $65 \%$ das empresas estão localizadas em apenas duas unidades federação: São Paulo e Minas Gerais. Contudo, os índices HHI recalculados para os dados da Tabela 7 apresentaram valores consideravelmente mais baixos, entre $0,23 \mathrm{e}$ 0,28. Há duas explicações possíveis para os indicadores de concentração mais baixos: i) a participação relevante de estados como Rio Grande do Sul, Rio de Janeiro, Pernambuco, Paraná e Santa Catarina; ii) A divisão relativamente equilibrada do número de empresas entre os estados líderes São Paulo e Minas Gerais.

Tabela 7 - Empresas de biotecnologia e biociências por região e por unidade da federação (\%)

\begin{tabular}{|c|c|c|c|c|c|c|}
\hline Região & UF/Fonte & ABDI (2012)* & $\begin{array}{c}\text { CEBRAP e BRBIOTEC } \\
(2011)^{*} \\
\end{array}$ & $\begin{array}{c}\text { Biominas e PwC } \\
(2011)\end{array}$ & $\begin{array}{c}\text { Biominas } \\
(2009) \\
\end{array}$ & $\begin{array}{c}\text { Biominas } \\
(2007) \\
\end{array}$ \\
\hline \multirow{4}{*}{$\begin{array}{l}\frac{0}{0} \\
\frac{0}{0} \\
\tilde{n}\end{array}$} & SP & $37 \%$ & $40,5 \%$ & $38 \%$ & $37,7 \%$ & $36,5 \%$ \\
\hline & $\overline{\mathrm{MG}}$ & $28 \%$ & $24,5 \%$ & $31 \%$ & $27,7 \%$ & $36,5 \%$ \\
\hline & RJ & $7 \%$ & $13 \%$ & $6 \%$ & $6,3 \%$ & $6,1 \%$ \\
\hline & $\mathrm{ES}$ & - & - & $1 \%$ & $0,4 \%$ & - \\
\hline \multirow{3}{*}{$\bar{\Xi}$} & $\mathrm{RS}$ & $12 \%$ & $8 \%$ & $7 \%$ & $7,5 \%$ & $6,6 \%$ \\
\hline & PR & $3 \%$ & $4,6 \%$ & $5 \%$ & $5,1 \%$ & $2,8 \%$ \\
\hline & SC & $2 \%$ & $1,3 \%$ & $3 \%$ & $2,4 \%$ & $1,1 \%$ \\
\hline \multirow{9}{*}{$\begin{array}{l}\frac{0}{0} \\
\frac{0}{0} \\
z\end{array}$} & $\mathrm{PE}$ & $7 \%$ & $4,2 \%$ & $3 \%$ & $2,4 \%$ & $3,3 \%$ \\
\hline & $\mathrm{CE}$ & $1 \%$ & $1,7 \%$ & $1 \%$ & $2,4 \%$ & - \\
\hline & $\mathrm{RN}$ & - & $0,4 \%$ & $1 \%$ & $0,4 \%$ & - \\
\hline & MA & - & - & - & - & - \\
\hline & PI & - & - & - & - & $0,6 \%$ \\
\hline & $\mathrm{PB}$ & - & - & - & - & - \\
\hline & $\mathrm{AL}$ & - & - & $1 \%$ & $0,4 \%$ & $0,6 \%$ \\
\hline & SE & - & - & - & - & - \\
\hline & BA & - & - & $1 \%$ & $0,8 \%$ & $0,6 \%$ \\
\hline \multirow{4}{*}{ 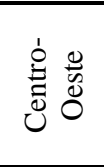 } & DF & - & $0,8 \%$ & - & $1,6 \%$ & $1,7 \%$ \\
\hline & $\mathrm{GO}$ & $1 \%$ & $0,8 \%$ & $3 \%$ & $2 \%$ & $1,1 \%$ \\
\hline & MS & - & - & - & $0,4 \%$ & $0,6 \%$ \\
\hline & MT & - & - & - & $1,2 \%$ & $1,1 \%$ \\
\hline \multirow{7}{*}{$\begin{array}{l}\frac{0}{0} \\
\text { Z }\end{array}$} & RO & - & - & - & - & - \\
\hline & $\mathrm{AC}$ & - & - & - & - & - \\
\hline & $\mathrm{AM}$ & $2 \%$ & - & $1 \%$ & $1,2 \%$ & $1,1 \%$ \\
\hline & $\mathrm{RR}$ & - & - & - & - & - \\
\hline & $\mathrm{PA}$ & - & - & - & - & - \\
\hline & AP & - & - & - & - & - \\
\hline & TO & - & - & - & $0,4 \%$ & \\
\hline \multicolumn{2}{|c|}{ Número de empresas } & 106 & 237 & 103 & 102 & 181 \\
\hline \multicolumn{2}{|c|}{ HHI } & 0,24 & 0,25 & 0,25 & 0,23 & 0,28 \\
\hline
\end{tabular}

*Empresas de biotecnologia

Fonte: Elaboração própria com base nos estudos listados na tabela. 
O estudo conduzido por CEBRAP e BRBIOTEC (2011) indica que as cidades com as maiores concentrações de empresas de biotecnologia são: São Paulo (18\%), Belo Horizonte (13\%), Rio de janeiro (12\%), Porto Alegre (5\%), Campinas (4\%), Ribeirão Preto (4\%), Viçosa (3\%), Recife (3\%) e Uberlândia (2\%). Cabe ressaltar que todas as cidades destacadas possuem universidades e instituições de ciência e tecnologia renomadas no contexto nacional.

A importância das interações com universidades e centros de pesquisa brasileiros para o surgimento e viabilização das empresas brasileiras de biociências e de biotecnologia é destacada em todos os estudos revisados. Entretanto, apenas CEBRAP e BRBIOTEC (2011) e Biominas (2009) forneceram estatísticas sobre interações universidade-empresa. De acordo com CEBRAP e BRBIOTEC (2011), cerca de 95\% das empresas de biotecnologia brasileira mantiveram interações ativas com universidades e centros de pesquisa. Destas, apenas 70\% mantiveram relacionamentos formais com instituições acadêmicas. Biominas (2009) corrobora esse percentual ao afirmar que $73 \%$ das empresas de biociências possuem relacionamentos formais com universidades. Entre os tipos de relacionamentos mais frequentes apontados pelas empresas se destacam: parcerias para o desenvolvimento conjunto de produtos e processos; utilização da estrutura física das universidades; contratação de estudantes e serviços especializados; licenciamento de tecnologias e treinamento de pessoal (Tabela 8).

Tabela 8 - Tipos de relacionamento universidade-empresa $(\%)$

\begin{tabular}{lcc}
\hline Fonte & CEBRAP e BRBIOTECH (2011)* & Biominas (2009) \\
\hline Co-desenvolvimento de produtos ou processos & $76,5 \%$ & $13,7 \%$ \\
\hline Licenciamento de tecnologias & - & $25,3 \%$ \\
\hline $\begin{array}{l}\text { Compartilhamento de infraestrutura } \\
\text { (Empresas utilizando a estrutura da universidade) }\end{array}$ & $52,2 \%$ & $33,7 \%$ \\
\hline Contratação de serviços especializados & $44,1 \%$ & $25,3 \%$ \\
\hline Contratação de estudantes e bolsistas & & $25,3 \%$ \\
\hline Treinamento de pessoal ou consultoria de pesquisadores & $41,9 \%$ & - \\
\hline Cursos, conferências e outros & $22,1 \%$ & $9,5 \%$ \\
\hline Número de empresas & 145 & 102 \\
\hline *Empresas de biotecnologia & & \\
Fonte: Elaboração própria com base nos estudos listados na tabela. &
\end{tabular}

Incubadoras e parques tecnológicos proporcionam um ambiente protegido e propício para o desenvolvimento de novos projetos e para o crescimento de novas empresas de base tecnológica. Em alguns casos, as incubadoras de empresas oferecem serviços de suporte gerencial e financeiro às novas empresas. A incubação tende a facilitar o estabelecimento de contatos com investidores, agências governamentais e outros empreendedores que podem se transformar em potenciais parceiros (RAZAIE et al., 2008; CEBRAP. BRBIOTEC, 2011).

Os dados da Tabela 9 indicam que parcelas relativamente altas (entre 50\% e 60\%) das empresas de biociências e biotecnologia nacionais estavam incubadas ou eram empresas graduadas na época em que os estudos foram realizados. Os estudos que utilizaram a definição de biociências apresentam parcelas menores de empresas incubadas em comparação com estudos que adotam definições de biotecnologia. A constatação fica explícita no caso da Biominas (2007) que fornece porcentagem tanto para empresas de biociências incubadas (27\%), quanto para empresas de biotecnologia incubadas (35\%).

Tabela 9 - Relação com incubadoras de empresas (\%)

\begin{tabular}{|c|c|c|c|c|}
\hline Fonte & Incubadas & Graduadas & Nunca estiveram incubadas & Número de empresas \\
\hline Bianchi $(2013)^{* *}$ & \multicolumn{2}{|c|}{$60,40 \%$} & $39,60 \%$ & 92 \\
\hline CEBRAP e BRBIOTEC (2011)* & $30,30 \%$ & $20,00 \%$ & $49,70 \%$ & 145 \\
\hline Biominas (2009) & $19,00 \%$ & $16,20 \%$ & $64,80 \%$ & 102 \\
\hline \multirow{2}{*}{ Biominas (2007) } & $27,10 \%$ & \multicolumn{2}{|r|}{$72,90 \%$} & 181 \\
\hline & $35,21 \% *$ & \multicolumn{2}{|r|}{$64,80 \%$} & $71 *$ \\
\hline
\end{tabular}

*Empresas de biotecnologia; **Empresas dedicadas à biotecnologia.

Fonte: Elaboração própria com base nos estudos listados na tabela.

O estudo Biominas e PwC (2011) afirma que um dos principais gargalos para o desenvolvimento da indústria brasileira de biotecnologia é o acesso à infraestrutura adequada, especialmente no que se refere às exigências regulatórias de certificação de projetos e laboratórios. Os dados apresentados pelo estudo 
"revelam a dificuldade crescente em encontrar incubadoras com capacidade física adequada e disponibilidade de espaço, assim como em estabelecer infraestrutura própria fora das incubadoras" (BIOMINAS. PWC, 2011: p.41). Poucas incubadoras brasileiras possuem infraestrutura adequada às exigências do setor de biotecnologia, principalmente na área de saúde humana. Argumenta-se que existe, no país, um problema de lotação das incubadoras existentes que são insuficientes para acolher um número crescente de empresas sujeitas a longos ciclos de desenvolvimento e maturação.

No que concerne às fontes de recursos financeiros utilizadas pelas empresas de biociências e biotecnologia brasileiras, os dados da Tabela 10 apontam a intensa utilização de recursos próprios (capital societário e lucros reinvestidos) e de fontes públicas de recursos.

Os investimentos privados de risco (capital semente, capital empreendedor e investidores anjos) e as parcerias corporativas são fontes de recursos disponíveis no país, mas utilizadas por uma proporção limitada de empresas. Apenas $10 \%$ das empresas relataram ter recebido exclusivamente capitais privados e $28 \%$ declararam ter recebido ambos (recursos públicos e privados). A grande maioria das empresas (62\%) declararam não haver captado qualquer forma de recurso privado (ABDI, 2012). Algumas explicações plausíveis para a menor utilização dos recursos privados são: i) a relativa incompletude do mercado de investimento empreendedor no Brasil; ii) $\mathrm{O}$ caráter jovem, pequeno e pré-operacional de uma parcela grande das empresas de biociências brasileiras, adequadas a modalidades de investimento que são, no Brasil, supridas por fontes públicas de recursos de fomento. Bianchi (2013) destaca, ainda, que 68,47\% das empresas dedicadas à biotecnologia no Brasil são empresas controladas por capital nacional.

\section{Tabela 10 - Principais fontes de recursos utilizadas pelas empresas (\%)}

\begin{tabular}{|c|c|c|c|c|c|c|c|}
\hline Fonte & $\mathrm{N}$ & & $\begin{array}{l}\text { Capital } \\
\text { próprio }\end{array}$ & $\begin{array}{l}\text { Recursos não- } \\
\text { reembolsáveis }\end{array}$ & $\begin{array}{r}\text { Recursos } \\
\text { reembolsáveis } \\
\end{array}$ & Investidor & $\begin{array}{r}\text { Parceiro } \\
\text { corporativo } \\
\end{array}$ \\
\hline \multirow{2}{*}{ Biominas e PwC (2011)* } & \multirow{2}{*}{103} & P\&D & $58,00 \%$ & $69,00 \%$ & $31,00 \%$ & $19,00 \%$ & $11,00 \%$ \\
\hline & & Demais atividades & $75,60 \%$ & $45,30 \%$ & $24,40 \%$ & $18,60 \%$ & $9,30 \%$ \\
\hline \multirow[t]{2}{*}{ Biominas (2009) } & \multirow[t]{2}{*}{102} & & $\begin{array}{l}\text { Capital } \\
\text { próprio }\end{array}$ & $\begin{array}{r}\text { Subvenções e } \\
\text { financiamento do } \\
\text { governo } \\
\end{array}$ & $\begin{array}{r}\text { Financiamento } \\
\text { bancário }\end{array}$ & Investidor & Outros \\
\hline & & & $85 \%$ & $22,90 \%$ & $8,40 \%$ & $8,40 \%$ & $10,50 \%$ \\
\hline
\end{tabular}

*Empresas de biotecnologia; $\mathrm{N}$ = Número de empresas

Fonte: Elaboração própria com base nos estudos listados na tabela.

Questionadas sobre a utilização de recursos públicos, a grande maioria das empresas afirmou receber alguma forma de apoio público na forma de financiamento, fomento, isenções fiscais e demais incentivos provenientes de políticas públicas para o segmento (Tabela 11). De acordo com Biominas (2009), pelo menos, $50 \%$ das empresas utilizaram formas de fomento público; 9,9\% beneficiaram-se de programas de crédito facilitado; 5,5\% usufruíram de isenções fiscais e 5,5\% declararam ter recebido outras formas de incentivos públicos.

\section{Tabela 11 - Utilização de recursos públicos (\%)}

\begin{tabular}{|c|c|c|c|}
\hline \multirow{2}{*}{ Fonte } & \multirow{2}{*}{$\begin{array}{l}\text { Número de } \\
\text { empresas }\end{array}$} & Empresa captou recursos públicos? & \\
\hline & & Sim & Não \\
\hline ABDI (2012)* & 106 & $72 \%$ & $28 \%$ \\
\hline CEBRAP e BRBIOTEC (2011)* & 143 & $78,30 \%$ & $21,70 \%$ \\
\hline$\overline{\text { Biominas (2009) }}$ & 102 & $65,90 \%$ & $34,10 \%$ \\
\hline Bianchi (2013)*4 & 118 & $64 \%$ & $4 \%$ \\
\hline
\end{tabular}

${ }^{*}$ Empresas de biotecnologia; ${ }^{4} 31 \%$ das empresas não responderam

Fonte: Elaboração própria com base nos estudos listados na tabela.

Entre as fontes públicas de recursos utilizadas com maior frequência pelas empresas brasileiras de biotecnologia destacam-se os mecanismos de fomento e financiamento oferecidos pela Financiadora de Estudos e Projetos (FINEP), programas de apoio articulados por Fundações de Amparo à Pesquisa (FAPs) e programas no âmbito do Conselho Desenvolvimento de Científico e Tecnológico (CNPq). Por outro lado, os recursos do BNDES foram acessados por apenas $13 \%$ ou $14 \%$ das empresas, resultado esperado considerando-se a maior orientação da instituição às empresas nacionais de grande porte (Tabela 12). 
Tabela 12 - Fontes de recursos públicos por tipo de instituição (\%)

\begin{tabular}{|c|c|c|c|c|c|c|c|}
\hline Fonte & $\mathrm{N}$ & FINEP & FAPs & $\mathrm{CNPq}$ & BNDES & $\begin{array}{c}\text { Outras agências } \\
\text { nacionais }\end{array}$ & $\begin{array}{c}\text { Institutos } \\
\text { internacionais }\end{array}$ \\
\hline ABDI (2012) ${ }^{*}$ & 106 & $47 \%$ & $39 \%$ & $27 \%$ & $13 \%$ & \multicolumn{2}{|c|}{$24 \%$} \\
\hline CEBRAP e BRBIOTEC (2011) ${ }^{*}$ & 143 & $55,20 \%$ & $46,20 \%$ & $43,40 \%$ & $14,00 \%$ & $5,60 \%$ & $4 \%$ \\
\hline
\end{tabular}

*Empresas de biotecnologia; $\mathrm{N}=$ Número de empresas

Fonte: Elaboração própria com base nos estudos listados na tabela.

Um dos maiores obstáculos enfrentados pelas novas empresas de biotecnologia brasileiras é o acesso ao capital empreendedor, também denominado capital de risco ou venture capital (ABDI, 2012). Apenas $14,3 \%$ das empresas brasileiras de biotecnologia receberam investimentos de capital empreendedor até 2011. Este percentual, consideravelmente baixo, equivale a 20 empresas em uma amostra de 140 empresas que responderam ao questionário da pesquisa de campo conduzida por CEBRAP e BRBIOTEC (2011). Bianchi (2013) argumenta que apesar desse percentual ser inferior à porcentagem de empresas que receberam recursos públicos, não é possível identificar relações de substitutibilidade ou complementariedade entre as duas fontes de recursos, pois não é possível averiguar se as empresas comtempladas são as mesmas. Cabe destacar que CEBRAP e BRBIOTEC (2011) não fazem qualquer distinção explícita entre o capital de risco público e o capital de risco privado. É possível que haja algum grau de complementariedade entre as duas fontes de financiamento em função da atuação da Finep e do BNDES, desde 1999, na criação de fundos de venture capital e em operações diretas de investimento de risco através do BNDES-PAR e do FIP INOVA EMPRESA (BIOMINAS. PWC, 2011).

O estudo da Biominas (2009) revela a elevada proporção dos investimentos de capital empreendedor nos estágios iniciais de concepção (estágio semente) e no estágio startup ${ }^{8}$ que representariam, conjuntamente, em número de operações cerca de $58 \%$ dos investimentos de risco em empresas de biociências (Tabela 13). A elevada participação relativa dos investimentos nas fases iniciais de desenvolvimento das empresas, principalmente no estágio semente $(29,2 \%)$, pode ser um indicativo da participação de fundos públicos de capital empreendedor e de investimento anjo. A justificativa reside no fato do venture capital privado ser um mecanismo de investimento mais adequado aos estágios em que as empresas já possuem fluxos de caixa ascendentes, ainda que negativos (LEONEL, 2014). No caso da biotecnologia, especialmente na área de saúde humana onde o risco técnico é elevado e o período de desenvolvimento de novos compostos terapêuticos é bastante longo, o estágio adequado ao capital de risco pode demorar anos para ser alcançado. Nestes casos, o investimento de risco privado pode depender de perspectivas de mercado muito favoráveis ou expectativas de lucro potencial extremamente elevadas ${ }^{9}$.

Tabela 13 - Estágio em que ocorreu o investimento empreendedor \% (Biominas, 2009)

\begin{tabular}{cccc}
\hline Concepção & Startup & Expansão inicial & Maturidade \\
\hline $29,2 \%$ & $29,2 \%$ & $33,3 \%$ & $8,3 \%$ \\
\hline
\end{tabular}

Número de empresas $=15$

Fonte: Elaboração própria com base em Biominas (2009)

Estima-se que entre 2001 e 2011 tenham sido investidos cerca de R \$ 100 milhões nas empresas brasileiras de biociências através de fundos regulamentados pela Comissão de Valores Mobiliários (CVM) (BIOMINAS. PWC, 2001). Bianchi (2013) argumenta que os valores investidos em empresas de biotecnologia podem ser considerados relativamente altos, considerando-se a imaturidade do mercado de capital de risco brasileiro. Biominas e PwC (2011), por outro lado, apontam que o valor total investido ao longo de uma década e o valor médio das operações são baixos se comparados aos investimentos realizados em outras regiões do mundo.

Razaie et al (2008) identificam alguns fatores que contribuem para a escassez de investimento de risco em empresas de biotecnologia no Brasil. Entre os fatores, destacam-se: i) a ausência de conhecimento

\footnotetext{
${ }^{8}$ Leonel (2014) define o estágio startup como a fase onde a empresa já possui um protótipo ou um produto em fase final de desenvolvimento, podendo inclusive ser lançado no mercado ou colocado na fase de testes regulatórios. Nesta etapa o faturamento das empresas é baixo e a receita é oscilante, permanecendo os fluxos de caixa negativos. A estrutura física ainda é frágil e reduzida, podendo ser compartilhada com universidades e incubadoras. O estágio startup é caracterizado por um grau de risco do empreendimento bastante elevado.

${ }^{9}$ Condições que foram marcantes no mercado de risco americano ao longo do período que antecedeu a bolha da internet no ano 2000 , que desestabilizou os mercados de capitais e impactou as condições de investimento em empresas promissoras a partir de então (LEONEL, 2014; CORIAT et al., 2003).
} 
e informação adequada sobre o segmento da biotecnologia no Brasil; ii) a elevada aversão ao risco dos investidores brasileiros; iii) questões jurídicas que implicam na responsabilização de investidores por possíveis ações tomadas pelas empresas investidas; iv) as elevadas taxas de juros e o forte desempenho do mercado financeiro brasileiro, que diminuem o incentivo à realização de investimentos de alto risco em empresas cujo retorno esperado é demorado; v) ausência de estratégias viáveis de saída do investidor de risco através da oferta pública de ações ou venda estratégica de ações das empresas de biotecnologia investidas, operações cuja frequência histórica no mercado brasileiro é baixa.

No que concerne à rede de colaborações, Razaie et al. (2008) afirmam que apesar da elevada colaboração entre empresas de biotecnologia e universidades locais, há poucos indícios de parcerias de colaboração entre empresas domésticas para realização conjunta de atividades de P\&D. Biominas e Pwc (2011) ratificam o argumento de baixo aproveitamento de parcerias corporativas. As empresas brasileiras de biociências não interpretam as parcerias corporativas como sendo um fator determinante para o sucesso e nem uma fonte crítica de financiamento para suas atividades, demonstrando aparente desalinho com as tendências mundiais (BIOMINAS. PWC, 2011). Razaie et al. (2008) creditam a escassez de parcerias de colaboração estratégica entre as empresas brasileiras de biotecnologia e grandes empresas nacionais a questões culturais. Segundo o autor, fatores como: a tendência cultural à valorização do que é estrangeiro; o caráter jovem das empresas de biotecnologia que ainda trabalham para construir suas capacitações internas; e a própria falta de conhecimento sobre a indústria de biotecnologia e sobre potenciais parceiros contribuem para a baixa frequência de interações.

Por outro lado, Bianchi (2013) identifica a existência de diversos casos de cooperação entre empresas brasileiras dedicadas à biotecnologia e parceiros internacionais. As parcerias com empresas estrangeiras são, contudo, limitadas às relações de comercialização e provisão de serviços, e, poucas vezes, envolvem acordos conjuntos de PD\&I (RAZAIE et al., 2008). Bianchi (2013) alerta para os casos das empresas Biobrás e Alellyx, cuja cooperação conduziu as empresas a uma trajetória final de aquisição pelas parceiras estrangeiras NovoNordisk e Monsato, implicando na desacumulação de capacitações locais.

Por um lado, os processos de aquisição de empresas de biotecnologia brasileiras - subsidiadas e fomentadas com recursos públicos - por parceiras estrangeiras evidencia uma tendência mundial da indústria de biotecnologia. Por outro lado, a questão explicita a necessidade de mecanismos institucionais que propiciem as parcerias cooperativas como um meio de construção de capacidades de inovação, mas que limitem operações que resultem na destruição de competências e capacitações locais em inovação.

Neste ponto, é válido ressaltar que a atuação do BNDES e da FINEP na função de investidores diretos de risco e na da criação de fundos de capital empreendedor públicos ou híbridos (através de parcerias com investidores públicos e privados) pode ser considerada uma alternativa possível para lidar com a questão das aquisições de empresas fomentadas com recursos públicos por parceiros estrangeiros. As operações de investimento de risco público envolvem, assim como o venture capital privado, a aquisição de participação acionária nas empresas investidas (o que não ocorre nos casos dos editais de subvenção e empréstimo de recursos não reembolsáveis). A aquisição, ainda que minoritária, das empresas pode ser uma forma de socializar os retornos futuros das empresas, evitando a socialização apenas dos riscos através da concessão de recursos não reembolsáveis. O argumento apoia-se na lógica de compartilhamento de riscos e retornos (risk-reward nexus) proposta por Lanzonick e Mazzucato (2014).

A existência limitada de padrões virtuosos de colaboração na indústria de biotecnologia brasileira pode ser verificada com base em processos de transferência de tecnologia e inovações abertas realizadas entre empresas através de esforços conjuntos de pesquisa e desenvolvimento. Os dados dispostos na Tabela 14 indicam que poucas empresas utilizam mecanismos de transferência de tecnologia, reforçando a hipótese de baixa intensidade de colaboração no sistema de inovação em biotecnologia no Brasil, especialmente no que concerne a interação entre empresas. Cerca de 23 empresas licenciaram alguma patente detida por universidades e centros de pesquisa. O número de empresas que realizaram algum tipo de inovação aberta com outras empresas é um pouco maior, cerca de 30 empresas. O licenciamento de patentes entre empresas é quase inexistente no país. O único elemento utilizado com maior frequência pelas empresas é o compartilhamento da infraestrutura de ICTs. A maior proximidade entre os pesquisadores tende a aumentar a transferência de conhecimentos tácitos e a colaboração na solução de problemas característicos do 
processo de inovação. Neste caso, a principal dificuldade apontada pelas empresas no licenciamento de tecnologias é a morosidade dos processos internos das ICTs brasileiras (ABDI, 2012).

Tabela 14 - Transferência de tecnologia por modalidades \% (ABDI, 2012)

\begin{tabular}{lrrr}
\hline & Sim & Não & Não respondeu \\
\hline Licenciou patente de alguma ICT brasileira? & $22 \%$ & $74 \%$ & $4 \%$ \\
\hline Licenciou patente de outra empresa? & $8 \%$ & $86 \%$ & $6 \%$ \\
\hline Licenciou patente para outra empresa? & $5 \%$ & $86 \%$ & $9 \%$ \\
\hline Já fez inovação aberta com outra empresa? & $28 \%$ & $59 \%$ & $13 \%$ \\
\hline Utiliza infraestrutura de ICT & $61 \%$ & $32 \%$ & $7 \%$ \\
\hline
\end{tabular}

Número de empresas $=106$

Fonte: Elaboração própria com base em ABDI (2012)

As patentes representam um importante ativo econômico para as empresas de biotecnologia. Além de indicarem o grau de inovação tecnológica na qual as empresas estão envolvidas, a detenção de direitos de propriedade intelectual é uma importante fonte de credibilidade para os empreendedores frente a investidores e parceiros corporativos e uma fonte alternativa de faturamento para as empresas que as detém e se dispõem a licenciá-las. A propensão a patentear, contudo, é baixa no Brasil. Os dados consolidados na Tabela 15 indicam que entre $15 \%$ e $44 \%$ das empresas nacionais de biociências depositaram pedidos de patentes no Instituto Nacional da Propriedade Intelectual (INPI). As porcentagens representam uma média de 30 empresas que detém pelo menos um pedido de patente no escritório brasileiro. Cerca de 15 empresas possuem patentes já concedidas pelo INPI (11\% a 16\% do total de empresas de cada estudo). A proporção de empresas que depositaram patentes em escritórios internacionais é consideravelmente mais baixa, entre $11 \%$ e $23 \%$, o que representa cerca de metade do número de empresas que realizaram pedidos de patente no INPI. O estudo da Biominas (2009) apontou a existência de uma curiosa correlação entre interações universidade-empresa e o depósito de patentes: "66\% das que interagem com ICTs depositaram, ao menos, uma patente, enquanto a atividade de depósito de patentes entre as empresas que não interagem foi bem menor, de 25\%" (BIOMINAS, 2009: p.7).

Tabela 15 - Percentual de empresas que possuem depósitos de patentes ou patentes concedidas (\%)

\begin{tabular}{|c|c|c|c|c|c|}
\hline \multirow[t]{2}{*}{ Fonte } & \multirow{2}{*}{$\begin{array}{l}\text { Número de } \\
\text { empresas }\end{array}$} & \multicolumn{2}{|c|}{$\begin{array}{c}\text { Empresas com pedidos de patentes } \\
\text { depositados }\end{array}$} & \multicolumn{2}{|c|}{$\begin{array}{l}\text { Empresas com patentes } \\
\text { concedidas }\end{array}$} \\
\hline & & No Brasil & No Exterior & No Brasil & No Exterior \\
\hline ABDI (2012) ${ }^{*}$ & 106 & $36 \%$ & $16 \%$ & $11 \%$ & $8,00 \%$ \\
\hline CEBRAP e BRBIOTEC (2011) ${ }^{*}$ & 144 & $27 \%$ & $16 \%$ & $13 \%$ & $9 \%$ \\
\hline Biominas e PwC (2011) & 88 & $44 \%$ & $23 \%$ & $18 \%$ & $13 \%$ \\
\hline Biominas (2009) & 102 & $27,60 \%$ & $11,50 \%$ & $16,10 \%$ & $9,20 \%$ \\
\hline Biominas (2007) ${ }^{*}$ & 71 & $15,50 \%$ & - & - & - \\
\hline
\end{tabular}

*empresas de biotecnologia

Fonte: Elaboração própria com base nos estudos listados na tabela.

O baixo grau de patenteamento dentre as empresas nacionais de biotecnologia e biociências suscita dúvidas sobre a competitividade do segmento e sobre a qualidade da estrutura institucional brasileira. Fatores como a baixa compreensão sobre os mecanismos de proteção de direitos de propriedade intelectual, o baixo grau de geração de inovações em biotecnologia no Brasil e o elevado número de empresas prestadoras de serviços - não focadas no desenvolvimento de produtos e processos proprietários - são apontados por Biominas (2009) como possíveis explicadores para a baixa proporção de empresas com pedidos de patente no INPI. Um grande obstáculo às empresas que realizam depósitos no INPI é o longo prazo para análise e concessão do documento de patente (backlog) que pode chegar a até 15 anos. A legislação restritiva sobre a definição de itens patenteáveis; a restrição à exploração da biodiversidade brasileira; e o custo do processo de depósito das patentes também são apontadas como obstáculos pelo público empresarial brasileiro (BIOMINAS. PWC, 2011; BIOMINAS, 2009). No caso dos escritórios internacionais, os custos do processo de depósito e da manutenção de patentes internacionais atuam como desestímulos aos empreendedores brasileiros. Os documentos de patentes não são o único mecanismo de proteção de propriedade intelectual. Muitas empresas optam pela alternativa de segredo industrial. Apesar das patentes serem utilizadas frequentemente como um indicador de invenções e inovações, essas não 
devem ser consideradas um indicador perfeito em função dos muitos itens não serem patenteáveis e da opção de muitas empresas em não patentear suas descobertas e invenções.

\section{Resultados da identificação de empresas com aplicações em saúde humana}

A pesquisa identificou 271 empresas brasileiras de biociências ${ }^{10}$. O processo de identificação partiu de uma listagem contendo 372 razões sociais levantadas com base nas fontes descritas na seção metodológica. Excluíram-se 101 nomes de empresas e instituições por variadas razões: 32 empresas foram excluídas por ausência ou insuficiência de informações; 12 empresas foram excluídas por fortes indícios de extinção ou liquidação; 13 razões nomes foram excluídos por consistirem em nomes de associações, laboratórios oficiais ou instituições de apoio à pesquisa científica e tecnológica; 10 grandes empresas nacionais foram excluídas da amostra (em sua maioria empresas farmacêuticas nacionais e grandes jointventures farmacêuticas); 14 empresas multinacionais foram excluídas da amostra; 20 empresas foram excluídas da amostra por não estarem adequadamente enquadradas no conceito de biociências.

Todos os sites institucionais das 271 empresas foram individualmente verificados. Estima-se que $79,3 \%$ empresas da amostra dispunham de sites em atividade. Foram encontrados avisos de em construção em 6 casos. O status site em construção está relacionado à manutenção temporária da página web ou à estágios iniciais de desenvolvimento das empresas. Em 26 casos as empresas apresentaram sites inativos. Em 18 casos as empresas não tiveram sites identificados. A inatividade ou inexistência do site institucional pode ser um indicador da existência de empresas em estágios muito iniciais de desenvolvimento ou de empresas que encerraram suas atividades, ainda que não tenham dado baixa em seus CNPJ. Dentre as 50 empresas cujos sites não puderam ser visitados, apenas 11 possuem mais de 10 anos de existência. A literatura acadêmica revisada indica a existência de um vale da morte caracterizado por elevados níveis de fracasso e extinção de empresas novas que enfrentam riscos elevados e que não conseguem se sustentar no mercado (MCKELVEY et al, 2004; PISANO, 2010). A indisponibilidade do site foi desconsiderada como critério para exclusão de empresas da amostra. Muitas empresas com sites indisponíveis encontravam-se incubadas e possuíam CNPJ ativos durante o período de condução da pesquisa. O status inativo dos sites pode, contudo, indica a possibilidade de a amostra de empresas estar sobrestimada.

Entre as 271 empresas brasileiras de biociências identificadas: 137 possuem aplicações em saúde humana (50,5\%); 100 são empresas voltadas ao agronegócio (saúde animal, bioenergia e agricultura; $36,9 \%) ; 19$ empresas estão orientadas a aplicações em meio ambiente $(7,0 \%) ; 28$ empresas se dedicam à pesquisa e produção de insumos (10,3\%); e 48 são empresas mistas com aplicações em múltiplos segmentos $(17,7 \%)$. Há dupla contagem nos dados em função da possibilidade de orientação das empresas a mais de um setor de atividade.

Das 137 empresas de biociências com aplicações em saúde humana, pelo menos em 21 casos $(17,5 \%)$ as empresas dedicam-se a mais de uma área de atividade. É frequente que as empresas voltadas à saúde humana também possuam aplicações em saúde animal. Este é o caso de, pelo menos, 12 empresas, inclusive três casos empresas voltadas ao controle e diagnóstico de dengue, zika e chikungunya ${ }^{11}$. Identificou-se em 4 dos 12 casos uma orientação mais voltada às atividades do agronegócio do que às aplicações em saúde humana. Observou-se, ainda, que empresas voltadas à validação de medicamentos genéricos com frequência realizavam também pesquisas de contaminação para controle ambiental. Foram identificadas 22 empresas de insumos voltadas à produção de reagentes, enzimas e kits de diagnóstico para atender demandas de saúde humana.

Foram identificadas 96 empresas de biotecnologia em saúde humana ${ }^{12}$. Da lista de 137 empresas de biociências com aplicações em saúde humana, excluíram-se 41 empresas: 14 empresas identificadas como Contract Research Organizations (CROs) farmacêuticas voltadas à realização de testes clínicos e à validação de medicamentos genéricos foram excluídas por ausência de indícios de utilização de técnicas de

\footnotetext{
${ }^{10}$ A lista completa de empresas brasileiras de biociências por área de atividade encontra-se disponível em Alves (2017), assim como a lista de empresas excluídas da amostra original com 372 razões sociais. Neste artigo são apresentados apenas os nomes fantasia das empresas do segmento de saúde humana.

${ }^{11}$ As empresas Ecovev, BR3 Agrobiotecnologia e Bthek Biotecnologia se dedicam à pesquisa e ao desenvolvimento de diagnósticos ou controles biológicos para o vetor da Dengue, Zica e Chikungunya. As empresas foram classificadas no segmento de agronegócios por se dedicarem a técnicas de controle biológico de pragas e insetos transmissores de doenças infecto contagiosas. Entretanto, as empresas estão envolvidas em demandas do complexo da saúde e desenvolvem tecnologias para diagnósticos e análise biológicas para o controle de doenças.

${ }^{12}$ Empresas que utilizavam pelo menos uma das técnicas de biotecnologia descritas no Quadro 1.
} 
biotecnologia ${ }^{13} ; 3$ três empresas de base farmoquímica; 5 empresas dedicadas à fitoterápicos; 2 empresas produtoras de alimentos proteicos e probióticos; 2 laboratórios clínicos que não realizam análises genéticas, celulares e que não estão envolvidos em $\mathrm{P} \& \mathrm{D}$ de novos diagnósticos; 5 empresas dedicadas à pesquisa e desenvolvimento de dispositivos médicos e odontológicos e 6 empresas voltadas à produção e ao desenvolvimento de dermocosméticos ${ }^{14}$.

Das 96 empresas brasileiras de biotecnologia com aplicações em saúde humana identificadas: 82 empresas estão localizadas na região sudeste que concentra $85 \%$ da amostra nos estados de São Paulo (38), Minas Gerais (29) e Rio de Janeiro (15); 9 empresas estão na região Sul e 5 empresas estão espalhadas pelas demais regiões do país. O mapa de empresas é apresentado na Figura 1.

\section{Figura 1 - Mapa de empresas brasileiras de biotecnologia em saúde humana}

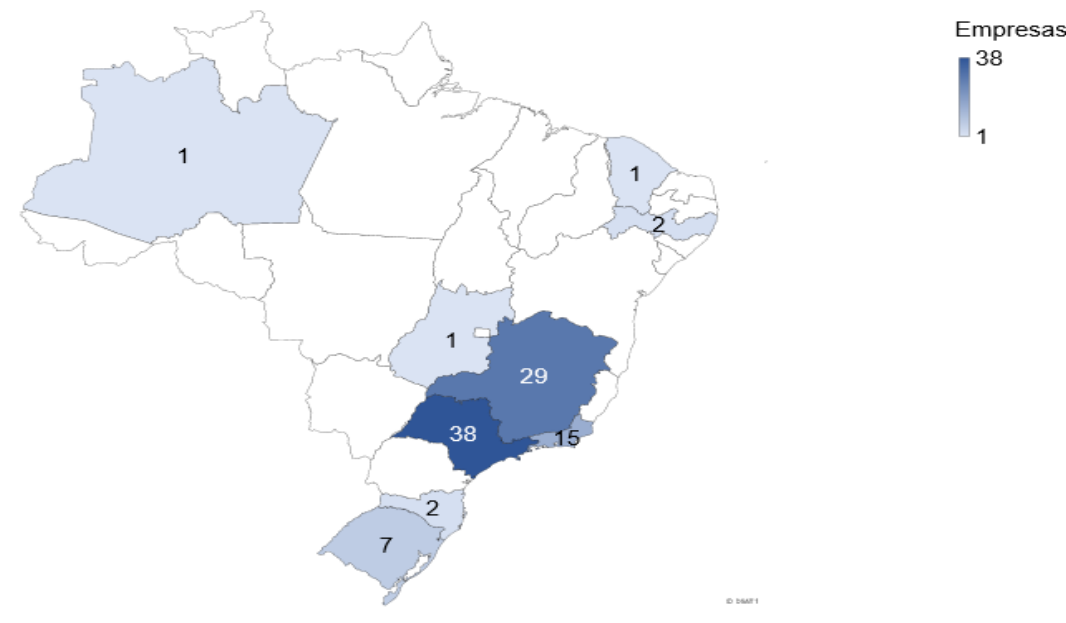

Fonte: Elaboração Própria

As empresas identificadas eram, em sua maioria, empresas jovens. Das 96 empresas, 71 (74\%) foram criadas após o ano 2000 e 16 (17\%) após o ano 2010; apenas 25 empresas da amostra foram registradas no período compreendido entre os anos 1972 e 1999. A dispersão de empresas por ano de criação é apresentada na Figura 2.

Figura 2 - Dispersão de empresas de biotecnologia em saúde humana por ano de criação

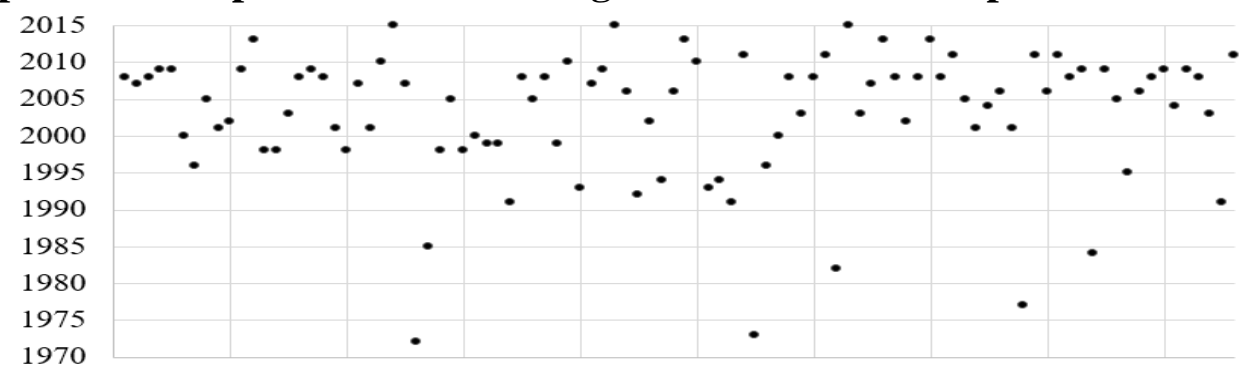

Fonte: Elaboração Própria

Apenas 26 empresas de biotecnologia em saúde humana encontravam-se classificadas como empresas interativas com universidades de acordo com o Censo 2010 do diretório dos grupos de pesquisa do CNPq. O indicador de $27 \%$ empresas interativas é consideravelmente inferior aos indícios de relacionamento universidade-empresa apresentados na Tabela 8. A baixa proporção de empresas interativas no CNPq pode ser consequência: (i) Das 16 empresas criadas após o ano 2010; (ii) Do fato da base de dados do CNPq ser baseada em declarações voluntárias dos grupos de pesquisa que interagiram com empresas.

\footnotetext{
${ }^{13}$ Não é descartada a possibilidade de que algumas dessas empresas possuam capacitações em biotecnologia, entretanto os indícios encontrados no período de condução desta pesquisa não eram suficientes para justificar a inclusão destas na lista de empresas de biotecnologia.

${ }^{14}$ Empresas excluídas: Accert, Advance Pharma, Ans Pharma, Baktron Microbiologia, Biocinese, ATCGen Biotecnologia, Cemsa, Galeno Research, In Vitro Cells, Intrials Pesquisa Clínica, Medcin Instituto da Pele, Narcissus Pesquisa Clínica e Biotecnologia, Trymed-Biocancer, Visionaltech, Alpha BR, Essenti, Zelus, Lychnoflora, Nanofitotec, Sauad, Phytobios, Sourcetech, Edetec e Nuteral, Instituto Hermes Pardini, Laboratório Geraldo Lutosa, Angelus, Aptivalux, Axoon, Biokyra e Mediphacos, Biologicus, Biorosam, Biosim, Brasco, Bravir, BS Pharma, respectivamente.
} 
As empresas encontram-se catalogadas sob 22 Códigos CNAE distintos ${ }^{15}$. A grande diversidade de códigos é provavelmente consequência da transversalidade das aplicações e da dificuldade na definição das atividades de biotecnologia em um único código. Portanto, a utilização de códigos CNAE como proxy para identificar empresas de biotecnologia em saúde humana não é recomendável.

As empresas foram agrupadas em quatro grandes categorias de acordo com suas atividades: i) Grupo 1 - Múltiplas técnicas de biotecnologia em saúde humana; ii) Grupo 2 - Engenharia tecidual e biomateriais; iii) Grupo 3 - Enzimas e kits de diagnóstico; iv) Grupo 4: Laboratórios clínicos e bancos de células.

O primeiro grupo engloba 45 empresas ${ }^{16}$ com aplicações em: anticorpos policlonais, monoclonais e sintéticos; medicamentos e vacinas anti-retrovirais; tratamentos oncológicos e neurológicos; produção de hormônios; terapia gênica e celular; técnicas de DNA e RNA recombinantes; drogas anti-microbianas; busca por novas moléculas e compostos terapêuticos; síntese de proteínas para a produção de biofármacos e manipulação de células tronco. Esse agrupamento é o mais amplo em número de técnicas e, portanto, conta com o maior número de empresas identificadas. A proporção de empresas criadas após o ano 2000 é de $89 \%$ e $67 \%$ possuem menos de 10 anos de atividade. A região sudeste do país concentra $76 \%$ das empresas do grupo. Estima-se que 39\% das empresas identificadas no Grupo 1 mantinham interações com ICTs (empresas interaticas CNPq) e 60\% delas estão catalogadas sob o código Pesquisa e Desenvolvimento Experimental em Ciências Físicas e Naturais (7210-0/00). As demais empresas estão classificadas sob dez códigos CNAE diferentes.

O segundo grupo de empresas é composto por 15 empresas ${ }^{17}$ dedicadas à pesquisa e desenvolvimento de biomateriais, especialmente enxertos para a regeneração óssea e biomembranas para tratamento de úlceras e curativos. Estima-se que a região sudeste que concentra $87 \%$ das empresas do Grupo 2, 80\% da amostra foi registrada após o ano 2000 e $47 \%$ possuem menos de 10 anos de funcionamento. O percentual de empresas interativas (CNPq) no grupo é de 40\%. O código CNAE mais frequente entre o grupo de empresas é fabricação de materiais para medicina e odontologia (3250-7/05) que representa 33\% do grupo. O segundo código CNAE mais frequente é pesquisa e desenvolvimento experimental em ciências físicas e naturais (7210-0/00), sob o qual estão catalogadas $20 \%$ das empresas. As demais empresas estão catalogadas sob cinco códigos CNAE diferentes.

O terceiro grupo é composto por 16 empresas ${ }^{18}$ voltadas à pesquisa, ao desenvolvimento e à produção de enzimas, reagentes e kits de diagnóstico para doenças infecciosas, negligenciadas e sexualmente transmissíveis. A maioria das empresas do segmento estão localizadas na região sudeste, a única exceção é uma empresa localizada no Estado de Goiás. As empresas de biotecnologia voltadas à produção de enzimas, reagentes e kits de diagnóstico constituem o grupo de empresas com a maior proporção de empresas experientes no mercado. Estima-se que 63\% das empresas do segmento estão no mercado a mais de 16 anos. Apenas 37\% da amostra teve o CNPJ registrado após o ano 2000. Nenhuma empresa foi criada após 2010. Uma explicação para o fenômeno é o fato de existirem na amostra empresas de base química que se voltaram ao desenvolvimento e à produção de diagnósticos para doenças infecto contagiosas e sexualmente transmissíveis, como kits ELISA para diagnósticos de doenças autoimunes. O indicador de interação universidade-empresa é nulo para o grupo 3. Quando se analisam os códigos CNAEs, 40\% das empresas estão catalogadas sob o código de fabricação de preparações farmacêuticas (2123-8/00) e 20\% sob fabricação de materiais para medicina e odontologia (3250-7/50). As demais empresas encontram-se catalogadas sob cinco códigos CNAEs diferentes.

\footnotetext{
${ }^{15}$ Códigos CNAE identificados: 3250-7/05; 8640-2/01; 2029-1/00; 2031-2/00; 2099-1/99; 2110-6/00; 2121-1/01; 2123/8-00; 3250-7/01; 46443/01; 4645-1/01; 4773-3/00; 4789-0/99; 6461-1/00; 6911-7/03; 7120-1/00; 7210/0-00; 7490-1/99; 8599-6/99; 8630-5; 8640-2; 8650-0/99.

${ }^{16}$ ACTGene; Ampligenix Biotech; Bioaptus; Biocelltis; Biolotus Biotech; Biomm; Biotech Amazônia; Cellpraxis; CellProtect; Chron Epigen (DG-Labs); Dentillo e Gavio Identificação e Quantificação Molecular; Dnapta Biotecnologia; Excellion; Extracta; Fk Biotecnologia; Genpharma Consultoria Farmacêutica e Genética; Gentros; Proteogenética; Hygeia; Hystem Terapias Celulares; Imunoscam; Invent Biotecnologia; Isofitos; Labfar; Ludwig Biotecnologia; Nanophoton; Neoprospecta; PDT Pharma; Pharmapraxis; Pluricell Biotech; Proteimax; Proteobras; QuatroG; Real Biotec; Recepta Biopharma; Revolugenix Biotecnologia; Rheabiotech; Silvestre Labs; Stratego Bio; VellyFARM; Veritas Biotecnologia; Viriontech; Vitatec e Ziel Biosciences.

${ }^{17}$ Bioactive; Bionext; Biorepair; Ceelbio; Einco Biomaterial; Inside Materiais Avançados; JHS Laboratório Químico; Labcor Laboratórios; Tissuebond; Vitrovita; Osseocon Biomateriais; Oxbone; Pele Nova; Polimera indústria e Comercio e Polisa Biopolímeros para a Saúde.

${ }^{18}$ Biotecnica; Doles Reagentes; Engene Tech Farmacêutica e Biotecnologia; Gold Analisa Diagnóstica; In Vitro Diagnóstica; Intercientifica; Katal-Interteck e Labtest Diagnostica.
} 
O quarto grupo é constituído por laboratórios clínicos voltados à realização de testes, sequenciamentos e análises de DNA; diagnósticos genéticos e moleculares; testes paternidade; medicina reprodutiva humana; análises citogenéticas; e armazenamento de células-tronco. Foram identificadas 20 empresas $^{19}$, das quais 2 são clínicas de reprodução assistida e 2 são bancos de células tronco. Todas as empresas do grupo destinam-se prioritariamente à provisão direta de serviços ao público com a utilização de pelo menos uma técnica de biotecnologia. Apesar do foco prioritário em serviços, muitas das empresas identificadas mantêm departamentos de $\mathrm{P} \& \mathrm{D}$ ativos em sua estrutura. As empresas do grupo 4 não estão diretamente articuladas com o sistema de inovação em medicamentos biológicos. Entretanto, a construção de competências nas atividades de sequenciamento e análise genética molecular, bem como em técnicas de armazenamento de células tronco, são importantes para consolidação de uma infraestrutura local de ciência e tecnologia adequada às atividades de $\mathrm{P} \& \mathrm{D}$ e Inovação biofarmacêutica. Estima-se que $65 \%$ das empresas do grupo tenham sido criados após o ano 2000 e 5 laboratórios foram criados a partir de 2010 . Todas as empresas do segmento estão localizadas na região sudeste. Foi possível encontrar apenas 2 empresas interativas $(\mathrm{CNPq})$ na amostra de 20 laboratórios, refletindo um indicador de interação bastante reduzido para o segmento (10\%). A maioria dos laboratórios $(70 \%)$ encontram-se classificados sob códigos CNAE de atividades de atenção à saúde humana (8630-5, 8640-2 e 8650-0). As demais empresas estão classificadas sob os códigos de pesquisa e desenvolvimento experimental em ciências físicas e naturais (7210-0/00) e outras atividades profissionais, científicas e técnicas (7490-1/99).

A Tabela 16 sistematiza os resultados encontrados por grupos de empresas.

\section{Tabela 16 - Resultados por grupos de empresas de biotecnologia em saúde humana}

\begin{tabular}{c|c|c|c|c|c}
\hline Grupo de empresas & No de empresas $^{\text {Empresas }}$ & $\begin{array}{c}\text { Concentração na região } \\
\text { jovens (\%) }\end{array}$ & $\begin{array}{c}\text { Interação com grupos de } \\
\text { pesquisa do CNPq (\%) }\end{array}$ & CNAE mais frequentes \\
\hline Grupo 1 & 45 & $89 \%$ & $76 \%$ & $39 \%$ & $7210-0 / 00$ \\
\hline Grupo 2 & 15 & $80 \%$ & $87 \%$ & $40 \%$ & $3250-7 / 05$ e $7210-0 / 00$ \\
\hline Grupo 3 & 16 & $37 \%$ & $94 \%$ & $0 \%$ & $2123-8 / 00$ e 3250-750 \\
\hline Grupo 4 & 20 & $63 \%$ & $100 \%$ & $10 \%$ & 8630,8640 e 8650 \\
\hline
\end{tabular}

Fonte: Elaboração própria

\section{Considerações Finais}

A sistematização de dados provenientes de estudos técnicos e acadêmicos sobre biotecnologia e biociências no Brasil permitiu a construção de um panorama sobre empresas brasileiras de biotecnologia e de biociências. Estima-se que existem cerca de 300 empresas de biociências e entre 175 e 240 empresas de biotecnologia no Brasil. O limitado número de empresas indica a existência de uma indústria de biociências e biotecnologia ainda incipiente no país. As empresas brasileiras são: jovens; micro e pequenas; fortemente concentradas na região sudeste, especialmente no estado de São Paulo e Minas Gerais; especializadas na provisão de serviços biotecnológicos ou desenvolvedoras de produtos e processos; em fase pré-operacional e controladas majoritariamente por capital nacional. Outras características apontadas são: a forte relação com universidades e centros de pesquisa acadêmica e o elevado coeficiente de empresas incubadas e graduadas. As empresas voltadas à saúde humana correspondem a cerca de $40 \%$ das empresas identificadas pelos estudos revisados, representando a área de atividade com a maior concentração de empresas.

No Brasil, a presença do capital empreendedor (capital de risco ou venture capital) é limitada e acesso a fontes privadas de financiamento mostrou-se reduzido. As empresas brasileiras de biociências e de biotecnologia apontaram um modelo de financiamento mais intensivo na utilização de capital próprio e de fontes públicas de fomento e financiamento. As fontes públicas de recursos mais acessadas foram a FINEP, as FAPs e o programa RHAE do CNPq. Destacam-se as iniciativas da FINEP e do BNDES para a criação de fundos de capital de risco com utilização total ou parcial de recursos públicos como o INOVA Empresa e o CRIATEC, além das linhas de crédito reembolsáveis e não reembolsáveis.

Há poucos indícios de interações entre empresas de biociências e biotecnologia brasileiras e grandes empresas estabelecidas no Brasil, embora a interação com Instituições de Ciência e Tecnologia sejam

\footnotetext{
${ }^{19}$ Biocod Biotecnologia, Biogenetics, CATG Centro de Analise e Tipagem de Genomas, Ccb Centro de Criogenia, Centro Pró-Criar de Medicina Reprodutiva, Códon Biotecnologia, Cryopraxis Criobiologia, Genera Inovação em Saúde, Fertitech, Genoa Biotecnologia, Genomic Engenharia Molecular, Genotyping-Laboratórios de Biotecnologia, Helixxa, Immunogenic, Invitra, Multigene Pesquisa e Serviços em Genética, GeneMG, Onkos, Unigen Tecnologia do DNA, Visiogen Biotecnologia.
} 
intensas. Há indícios também de interações entre empresas brasileiras de biociências e biotecnologia e grandes empresas internacionais. As interações em âmbito internacional estão, contudo, associadas à possibilidade de aquisição das empresas brasileiras por grandes parceiras internacionais e a processos de desacumulação de capacitações locais. Esta é uma hipótese crítica em função dos esforços de fomento e financiamento público direcionados ao estímulo destas empresas no Brasil. A aquisição de participação acionária minoritária nas empresas pelas agências e bancos oficiais através de operações diretas de investimento empreendedor é apontada como uma alternativa possível para contornar a questão do paradoxo entre a socialização dos riscos - via fomento e subvenção pública às empresas em seus estágios iniciais de desenvolvimento - e a socialização dos retornos das empresas.

Os baixos níveis de colaboração na indústria brasileira de biociência e biotecnologia refletem-se na baixa utilização de mecanismos de transferência de tecnologia, como o licenciamento de patentes entre empresas. O mecanismo de patentes é utilizado por parcelas reduzidas das empresas brasileiras de biotecnologia e biociências. A baixo patenteamento suscita dúvidas sobre a competitividade e a capacidade de geração de invenções e inovações pelas empresas brasileiras de biociências e biotecnologia. O backlog de patentes, as limitações legais, os custos de depósito e manutenção de patentes e a existência de outros mecanismos de proteção da propriedade intelectual são apontados como possíveis explicações para a limitada atividade de patenteamento pelas empresas de biociências e biotecnologia brasileiras.

A metodologia de prospecção de empresas desenvolvida para este trabalho permitiu a identificação de 271 empresas brasileiras de biociências, 137 empresas brasileiras de biociências com aplicações em saúde humana e 96 empresas brasileiras de biotecnologia em saúde humana. A identificação das empresas é uma importante contribuição à literatura acadêmica por remover um ponto de estrangulamento que restringia a capacidade de realização de pesquisas voltadas às empresas de biotecnologia formadas sob o modelo de empreendimentos baseados em conhecimento inseridas no Sistema de Inovação Biofarmacêutico Brasileiro. $\mathrm{O}$ artigo apresenta uma classificação das empresas brasileiras de biotecnologia em saúde humana por grupos de atividade. A classificação facilita a apresentação dos dados ao leitor e permite identificar grupos de empresas com características similares. As empresas foram agrupadas em quatro grandes categorias de acordo com suas atividades. O Grupo 1 engloba 45 empresas envolvidas na utilização múltiplas técnicas de biotecnologia em saúde humana, especialmente técnicas de biotecnologia moderna. O Grupo 2 engloba 15 empresas envolvidas em engenharia tecidual e produção de biomateriais. O Grupo 3 é constituído por 16 empresas produtoras de enzimas e kits de diagnóstico, enquanto o Grupo 4 é constituído por 20 empresas que funcionam como laboratórios clínicos e bancos de células. Enquanto os grupos 1 e 2 apresentam as maiores proporções de empresas jovens e interativas com grupos de pesquisa acadêmica, os grupos 3 e 4 são altamente concentrados na região sudeste e apresentam baixo indício de interação com grupos de pesquisa do CNPQ. O grupo 3 destaca-se pela elevada concentração de empresas com mais de 16 anos de funcionamento que não apresentam qualquer indício de interação com os grupos de pesquisa do CNPq segundo os dados do Censo 2010. O grupo 4 encontra-se totalmente concentrado na região sudeste do país, provavelmente em função do componente de demanda que é crítico para as empresas prestadoras de serviços intensivos em conhecimentos. Apesar dos códigos CNAE não serem recomendáveis como proxy para prospecção de empresas de biotecnologia em saúde humana, eles parecem úteis na classificação dos grupos de atividade, especialmente no caso do grupo 4 dos laboratórios clínicos.

\section{Referências Bibliográficas}

AGÊNCIA BRASILEIRA DE DESENVOLVIMENTO INDUSTRIAL (ABDI). Estudo de Caso: Biotecnologia no Brasil. Sumário Executivo. Brasília. 2012.

ALVES, N. Um estudo prospectivo das empresas de biotecnologia em saúde humana no Brasil. Dissertação (Mestrado em Economia). Faculdade de Economia. Universidade Federal Fluminense. Niteroi. 2017

ARORA, A. GAMBARDELLA, A. The division of innovative labor in biotechnology. In: ROSEMBERG, N. et al (orgs). Sources of Medical Technology: Universities and Industry. Washington, DC: National Academy Press. p.188-208, 1995.

BIANCHI, C. A Indústria Brasileira de Biotecnologia: montando o quebra-cabeça. In: Revista Economia e Tecnologia (RET), v. 9, p. 99-116. 2013.

BIOMINAS BRASIL. PRICEWATERHOUSECOOPERS BRASIL (PWC). A indústria de biociências nacional: caminhos para o crescimento. Belo Horizonte, 2011. 
- A indústria de biociências nacional: caminhos para o crescimento. Diretório de empresas de biociências do Brasil. Belo Horizonte, 2011.

BIOMINAS BRASIL. SERVIÇO BRASILEIRO DE APOIO ÀS MICRO E PEQUENAS EMPRESAS (SEBRAE). Diagnóstico do Setor de biociências em Minas Gerais. Diretório de empresas. Belo Horizonte, 2014.

BRASIL. Lei Complementar $\mathrm{N}^{\circ} 123$ de 14 de dezembro de 2006.

BRINK, J. MCKELVEY, M. SMITH, K. Conceptualizing and measuring modern biotechnology. In: MCKELVEY, M.; RICKNE, A.; LAAGE-HELlMAN, J. (orgs). The Economics Dynamics of Modern Biotechnology. Edward Elgar Publishing, p.20-42. 2004.

CENTRO BRASILEIRO DE ANALISE E PLANEJAMENTO (CEBRAP). ASSOCIAÇÃO BRASILEIRA DE BIOTECNOLOGIA (BRBIOTEC). Brazil Biotech Map 2011. São Paulo. 2011.

CONSELHO NACIONAL DE DESENVOLVIMENTO CIENTÍFICO E TECNOLÓGICO (CNPq). Diretório Nacional dos Grupos de Pesquisa. Disponível em: < http://lattes.cnpq.br/web/dgp>. Acesso em: 25 de julho de 2016.

CORIAT, B.; ORSI, F.; WEINSTEIN, O. Does biotech reflect a new science-based innovation regime? In: Industry and Innovation, v.10, p.231-253. 2003.

ECONODATA. Disponível em: <http://www.econodata.com.br/>. Acesso em dezembro de 2016.

EMPRESAS.CNPJ. Disponível em: <http://www.empresascnpj.com/>. Acesso em dezembro de 2016.

FUNDAÇÃO BIOMINAS. Estudo de empresas de biociências do Brasil 2009. 2009.

Estudo de empresas de biotecnologia do Brasil. 2007

Parque nacional de empresas de biotecnologia. Belo Horizonte. 2001

GRAVAGLIA, C. MALERBA, F. ORSENIGO, L. Entry, market structure and innovation in a "history friendly" model of the evolution of the pharmaceutical industry. In: DOSI, G. MAZZUCATO, M. (Orgs) Knowledge Accumulation and industry evolution. The case of Pharma-Biotech. Cambridge University Press, P.234-266. 2006.

LANZONICK, W. MAZZUCATO, M. The risk-reward nexus in the innovation-inequality relationship: who takes the risks? Who gets the rewards?. In: Industrial and Corporate Change, v. 22, p. 10931128. 2014.

LEONEL, S. G. Mitos e Verdades sobre a Indústria de Venture Capital. Abril de 2014. 186f. Tese (Doutorado em Economia). Faculdade de Economia. Centro de Desenvolvimento e Planejamento Regional, Universidade Federal de Minas Gerais. Belo Horizonte, 2014.

MALERBA, F. MCKELVEY, M. Conceptualizing knowledge based entrepreneurship: Definition and model. In: MALERBA, F. et al (orgs). Dynamics of Knowledge-Intensive Entrepreneurship: Business strategy and public policy. Routledge Taylor \& Francis Group, p.19-48. 2016.

MCKELVEY, M. RICKNE, A. LAAGE-HELLMAN, J. Stylized facts about innovation processes in modern biotechnology. In: MCKELVEY, M. RICKNE, A.; LAAGE-HELLMAN, J. (orgs). The Economics Dynamics of Modern Biotechnology. Edward Elgar Publishing, p.43-76. 2004.

MIGLIOLI, J. Biotecnologia na região de Ribeirão Preto: um estudo sobre aglomeração de empresas. Dissertação (Mestrado Profissional). Faculdade de Medicina de Ribeirão Preto. Universidade de São Paulo. Ribeirão Preto. 2015.

ORGANIZAÇÃO PARA A COOPERAÇÃO E DESENVOLVIMENTO ECONÔMICO (OCDE). A framework for biotechnology statistics. 2005.

PISANO, G. The Evolution of Science-Based Business: Innovating How We Innovate. Harvard Business School, Working Paper, n 10-062. 2010.

REZAIE, R. FREW, S. SAMMUT, S. MALIAKKAL, M. DAAR, A. SINGER, P. Brazilian health biotech: fostering crosstalk between public and private sectors. In: Nature Biotechnology, v. 26, p.627-644. 2008.

SERVIÇO BRASILEIRO DE APOIO ÀS MICRO E PEQUENAS EMPRESAS (SEBRAE). Critérios de classificação de empresas: MEI - ME - EPP. Disponível em: <http://www.sebraesc.com.br/leis/default.asp?vcdtexto=4154>. Acesso em novembro de 2016.

SHANE, S. Academic Entrepreneurship: University Spinoffs and wealth creation. Edward Elgar Publishing Limited. 2004. 